9 Abstract

\title{
Formulation of the quantitative influence of local and overall initial deflections on load-bearing capacity of unstiffened welded square box section columns under axial compression
}

\author{
Xiang Chen ${ }^{\text {a }}$, Shozo Nakamura ${ }^{a},{ }^{*}$, Toshihiro Okumatsu ${ }^{\text {a }}$, Takafumi Nishikawa ${ }^{a}$ \\ ${ }^{a}$ Dept. of Civil and Environmental Eng., Nagasaki University, 1-14, Bunkyo-machi, Nagasaki 852-8521, Japan \\ *Corresponding author: Shozo Nakamura, E-mail address: shozo@nagasaki-u.ac.jp
}

Although it is well known that initial deflections have a significant influence on load-bearing capacity of unstiffened square box section columns under pure compression, their quantitative influence is not clear. In this study, 378 finite element models were analyzed to reveal the quantitative influence of local and overall initial deflections on load-bearing capacity. In the parametric analyses, nine combinations of the amplitude of the local and overall initial deflections were considered. In addition, normalized width-thickness and slenderness ratios were varied with ranges from 0.3 to 1.8 and from 0.3 to 1.5 , respectively. As a result, the initial deflection influence coefficient was proposed to describe the quantitative influence on load-bearing capacity and formulated as functions of the local and overall initial deflections, normalized width-thickness and slenderness ratios. The accuracy of the proposed formula was verified through the comparison with the FEA results including additional 108 FEA results with normalized slenderness ratio of 0.9 and 1.2.

1 Keywords: coupled buckling; load-bearing capacity; initial deflections; unstiffened square welded box section; axial compression; parametric formulae. 


\section{Introduction}

Thin-walled compression members suffer from buckling instability due to high slenderness and widththickness ratios $[1,2,3,4]$. It is also well known that initial deflections have a significant influence on buckling instability behavior $[5,6]$. Initial deflections, which consist of the local initial deflection on the plate and the overall initial deflection on the column, appear during the manufacturing and assembling. In addition, the amplitude is uncertain.

Many researchers had measured the amplitude of initial deflections of box section columns. In Usami's experiment [7], amplitudes of overall initial deflection on 19 welded box section columns were measured.

The maximum was $L / 1590$ and average was $L / 3850$, where $L$ was the column length. In Rasmussen's research [8] with six welded box section columns measured, their maximum and average amplitudes were $L / 546$ and $L / 1172$, respectively. Somodi and Kövesdi [9] had measured initial deflections on 49 welded steel columns made of various steel grades. The results show that a total of 23 columns had overall initial deflection amplitudes larger than $L / 1000$ and the average value of total 49 columns is $L / 945$. In Degée's research [10], the maximum and average were $L / 2500$ and $L / 3560$ for the overall initial deflection, respectively; the maximum value was $b / 250$ for the local initial deflection where $b$ was the width of the plate. In Shi's experiment [11], amplitudes of local initial deflection on four welded stub columns were measured. The maximum and average were $b / 341$ and $b / 512$, respectively. However, these values are much smaller than those allowed in some specifications such as $L / 1000$ of Chinese [12], American [13], Japanese [14], specifications and $b / 150$ of Japanese [14].

Many numerical studies aimed at investigating the influence of the initial deflection have been contributed. Kwon [15] investigated the effect of local initial deflection on load-bearing capacity of welded 
RHS columns undergoing coupled buckling. The increase of the local initial deflection from $b / 2000$ to $b / 100$ resulted in the reduction of the load-bearing capacity about $28.5 \%$. In Inose's study [16], the increase of the initial deflection from $b / 450$ to $b / 150$ led to the reduction of load-bearing capacity of welded box section columns up to $11.4 \%$. Lu Yang [17] emphasized that the local initial deflection had the more obvious influence on the structure with high normalized width-thickness ratio.

Ban [18] studied the influence of the overall initial deflection on the overall buckling behavior of welded box section steel columns. The increase of overall initial deflection from $L / 2500$ to $L / 1000$ resulted in a decrease of load-bearing capacity by about $7 \%$ on average. Coelho [19] conducted a series of numerical analyses to investigate the sensitivity of the load-bearing capacity to imperfection. Models with four different amplitude of the overall initial deflection, which are $L / 1000, L / 500, L / 250$ and $L / 125$, were analyzed. The increase of the overall initial deflection resulted in the $40 \%$ decrease of load-bearing capacity. Kang [20] studied the effect of overall initial deflection on load-bearing capacity of welded steel box columns by selecting two different values i.e. $L / 1000$ and $L / 500$ with the normalized slenderness ratios from 0.8 to 1.8 . The results revealed that with the increase of the overall initial deflection, the average and maximum of reduction on load-bearing capacity were about $7.2 \%$ and $9.4 \%$ respectively. Moreover, the influence of the overall initial deflection showed to be related to the normalized slenderness ratio. The maximum reduction appeared at the normalized slenderness ratio of 1.25 . 
deflection will lead to a significant influence on load-bearing capacity. More importantly, the sensitivity of the structure to the initial deflection is related with the normalized width-thickness and slenderness ratios.

Although many experiments and numerical analysis have been conducted, the quantitative influence of the initial deflections of such structure is still not clear. In this study, unstiffened welded square crosssection columns with S355 steel under axial compression were chosen as a target. Nonlinear finite element models were developed to analyze their load-bearing capacity. A variety of the normalized width-thickness and slenderness ratios were considered to cover the possible diverse range of columns. Various combinations of amplitude of the local and overall initial deflections were prepared for FE models. Based on the results of parametric analyses, initial deflection influence coefficient is proposed as a function of the initial deflections and the normalized width-thickness and slenderness ratios to describe the quantitative influence caused by the difference in amplitude of the local and overall initial deflections on the loadbearing capacity.

\section{Validation of FE modelling}

\subsection{Existing experiment on unstiffened box section columns}

Degée et al. conducted the experiments of six columns (S-series) [10]. Two specimens (W-series) were tested by Pavlovčič et al. [21]. Somodi and Kövesdi [9] also carried out twelve column tests; ten of them (W3-series) were introduced in this paper except two columns due to unknown residual stress value. All of the above-mentioned specimens were made of S355 steel. To further cover wider ranges of width-thickness and slenderness ratios, eight specimens (R-series) made of HT80 steel having high width-thickness and slenderness ratios tested by Usami [7] were also considered in FE model validation. Cross-section is 
each dimension except Pavlovčič's test. It should be noted that in Somodi's test, plate thickness of some A-specimen is a little different from B-specimen, the upper value is for the A-specimen and the other is for the B-specimen. The parameters $\lambda$ and $R$ are defined as Eq. (1) and (2), respectively,

(1)

(1)

$$
\begin{gathered}
\lambda=\frac{1}{\pi} \sqrt{\frac{\sigma_{y}}{E}} \frac{L}{r} \\
R=\frac{b}{t} \sqrt{\frac{12\left(1-v^{2}\right)}{k \pi^{2}} \frac{\sigma_{y}}{E}}
\end{gathered}
$$

where $\lambda$ is the normalized slenderness ratio, $R$ is the normalized width-thickness ratio; $\sigma_{y}$ is the nominal yield stress; $E$ is Young's Modulus; $L$ is the length of the column; $r$ is the radius of gyration; $b$ is the width of the plate; $t$ is the thickness of the plate; $v$ is the Poisson's ratio; and $k$ is the buckling coefficient.

The initial deflection was measured prior to the experiment as listed in Table.2. The maximum measured local initial deflection on the plate was $b / 250$ in Degée's test, $b / 520$ in Pavlovčič's test while local initial deflection was not measured for W3-series and R-series specimens. The overall initial deflection for W3-series specimens listed in Table.2 is the sum of out-of-straightness deflection and load eccentricity. The columns were tested under the pin-ended condition which can rotate only around one axis.

\subsection{FE modelling}

The general-purpose FEA software MSC.Marc was applied to the numerical analyses of load-bearing capacity of unstiffened box section columns. Thick shell element (No.75) [22] was used in the model. Since the meshing size and the shape of the elements have an influence on the accuracy of the calculation [23], the shape of the elements was made to be as square as possible and meshing size was made to be small enough. Moreover, considering the convenience of residual stress setting, plates were divided into twenty elements for parametric analysis as shown in Fig.2 (a). The von Mises yield criterion was adopted in the analysis. Bilinear model with strain hardening coefficient of $E / 100$ was used to describe the material 
property of S355, and trilinear model based on measured material property [7] was used for R-series

108 specimens. The Poisson ratio was set to 0.3 and 0.24 for S355 and HT80, respectively.

In order to set the boundary conditions, two nodes were set at the midpoint of the top and bottom

cross-sections. The central node was set as the main node and the other nodes in the cross-section as

subordinate nodes. Then the "RBE2" function [22] was used to connect the central node (master node) with the whole nodes at the cross-section (slave nodes). The RBE2 function can make a rigid link between the master node and a list of slave nodes. The nodes were located away from the column in order to take the dimension of the test equipment into consideration as shown in Fig.2 (b). Considering that the columns were tested with pin-ended supports around the weak axis " $y$ ", the rotation Y was free at both top and the bottom node as shown in Table.3. At the top node, displacement $\mathrm{Z}$ was set free so that the displacement 117 loading can be applied to the top main node. members. It was assumed to exist in every plate with compression in the middle area and tension at both 120 sides of the plate as shown in Fig. 3 to be in self-equilibrium condition. Values of tensile and compressive residual stresses for each specimen were set as listed in Table.4. Since less of conclusive residual stress value in Degée's research [10], a calibrated distribution (i.e. Model 6 in [10]), which resulted in the closest load-bearing capacity to experimental results, was used for specimens S1, S2 and S3. For the specimens tested by Somodi [9] (W3 series), the tensile and compressive residual stresses were determined referring to the values measured for specimens with the same cross section by Somodi [24]. For W-series specimens, measured compressive residual stress [21] of $130 \mathrm{MPa}\left(0.35 \sigma_{\mathrm{y}}\right)$ and $160 \mathrm{MPa}\left(0.43 \sigma_{\mathrm{y}}\right)$ for flange and web, 
arranged for tensile and compressive residual stress, respectively. Although it is known that residual stresses

129 are $b / t$ ratio dependent values, one residual stress distribution is assumed in the parametric analysis in order

130 to independently evaluate the influence of initial deflections on load-bearing capacity. Referring to

131 Fukumoto's statistics [26], assumed compressive stress was set to $0.25 \sigma_{y}$, which is the average value of 216

132 cases. The residual stress distribution input in every plate assumed for FE model in parametric analysis is

133 shown in Fig.4.

134 Images of overall and local initial deflection shapes are shown in Fig.5. Half-sinusoidal wave shape

135 expressed by Eq. (3) was assumed for the overall initial deflection. The double trigonometric function

136 shown in Eq. (4) was assumed for the local initial deflection. The number of half-wave $m$ were determined

137 by the aspect ratio of the plate to give the minimum buckling strength according to the elastic buckling

138 theory. Schematic illustration of initial deflections in the case of the specimen with $m=3$ is shown in Fig.6

139 as an example. The measured amplitude of the initial deflections is used for the FE modelling. For W3-

140 series and R-series specimens, the local initial deflection was assumed to be $b / 200$ according to Eurocode

$1413[25]$ since it had not been measured.

$$
\begin{gathered}
w_{g}=w_{g 0} \sin \frac{\pi z}{L} \\
\left\{\begin{array}{l}
w_{l}=w_{l 0} \sin \frac{m \pi z}{L} \cos \frac{\pi x}{b} \\
w_{l}=w_{l 0} \sin \frac{m \pi z}{L} \cos \frac{\pi y}{b}
\end{array}\right.
\end{gathered}
$$

146 where $w_{g 0}$ is the amplitude of overall initial deflection; $w l 0$ is the amplitude of local initial deflection; $m$ is

147 the number of half-sinusoidal wave giving the minimum buckling strength determined by the aspect ratio 
148 of the plate.

1492.3 Validation of the modelling

150 All the 26 columns listed in Table 1 were modeled, and their ultimate strengths were obtained. The 151 comparison between experiment and FEA results is shown in Fig.7 and Table 5. It can be seen that most of 152 the FEA results for Degée's test (S-series) were a little lower than experimental results. The possible reason 153 is that local initial deflection used in FE models is the measured maximum, which is greater than the real 154 value for most of the specimens. For Pavlovčič test (W-series), the FEA results shows good agreement with test results. For Smodi's test (W3-series), numerical analysis provides good prediction on load-bearing capacity with a little larger deviation than that of Pavlovčič test. It can be observed that the difference between FEA and test results of W3-80-5-2000A reached up to 11.89\% while difference on W3-80-5-2000B was small. Possible reason is that the same residual stresses and assumed local initial deflection were introduced for these two specimens, while their values may be different in tested specimens which resulted in $15.6 \%$ difference on load-bearing capacity $(0.74$ and 0.64$)$ between them. For R-series specimens with high width-thickness ratios, it can be observed that FE results are slightly lower than test results due to the relatively large local initial deflection assumed. The average and standard deviation of errors for all specimens are $2.50 \%$ and $4.07 \%$, respectively. Based on the above discussion, it was concluded that the

164 model could be used in the following parametric analysis with sufficient accuracy.

\section{Parametric analysis}

\subsection{Combination of the parameters}

To evaluate the quantitative influence of the initial deflections on the load-bearing capacity, 378 
local and overall initial deflections were prepared and analyzed. The dimension of cross-section, the normalized slenderness ratio $\lambda$ and normalized width-thickness ratio $R$ are listed in Table 6 . Seven different normalized slenderness and six width-thickness ratios are adopted with the range from 0.3 to 1.8 and from 0.3 to 1.5 , respectively, to cover a main part of the practice. Table 7 lists the combinations of the normalized 173 slenderness and width-thickness ratios. combinations of the amplitude of the local and overall initial deflections listed in Table 8 were considered. The Combi5 corresponds to the combination of the allowable initial deflections in the Japanese

177 specification [14].

\subsection{Influence of the local initial deflection}

Results of models with the normalized width-thickness ratio $R$ from 0.3 to 1.5 and constant normalized comparison of load-bearing capacities for different local initial deflection are shown in Fig.8. In the range of $R \leq 0.5$, the reduction on load-bearing capacity caused by increasing local initial deflection is less than

184 local initial deflection from $b / 450$ to $b / 75$.

In this study, initial deflection influence coefficient (IDIC) is introduced to describe the quantitative influence of the initial deflections and defined as a ratio of the load-bearing capacity of a model with each

187 Combi to that of the Combi5. The calculation of IDICFEA based on FEA results can be performed as follows.

$$
\mathrm{IDIC}_{\mathrm{FEA}}=\frac{F_{u, C o m b i-i}}{F_{u, C o m b i-5}}
$$

where the $F_{u}$ is the load-bearing capacity of the specimen. 
standard amplitude i.e. $b / 150$ is shown in Fig.9. It can be seen that IDIC decreases approximately linearly as the amplitude of local initial deflection increases. The decreasing slope is nearly the same for different amplitudes of the overall initial deflection. Therefore, linear regression analysis is conducted on the data when the amplitude of the overall initial deflection is $L / 1000$.

The decreasing slope $\alpha$ is related to normalized width-thickness ratios as shown in Fig.10, in which seven series of data with different normalized slenderness ratios are plotted. It can be seen that the decreasing slope increases first and then decreases with the increase of the normalized width-thickness ratio. Since the decreasing slope represents the reduction of load-bearing capacity by local initial deflection, the peak points show the width-thickness ratio where the reduction reaches the maximum. In addition, the peak point of the decreasing slope $\alpha$ tends to move to larger width-thickness ratio with the increase of normalized slenderness ratios. When the normalized width-thickness ratio $R$ is small (i.e., $R \leq 0.5$ ), the influence of the local initial deflection seems to be slight. In the range of $R$ from 0.7 to 1.5 , column strength becomes comparatively sensitive to the local initial deflection. When normalized slenderness ratio $\lambda$ is small (i.e., $\lambda \leq 0.5$ ), the influence reaches the maximum with the decreasing slope about 0.1 at $R=0.7$. It corresponds to the $17.2 \%$ decrease of the load-bearing capacity. When $\lambda$ is large (i.e., $\lambda \geq 1.0$ ), the load-bearing capacity of 206 columns with higher $R$-value becomes sensitive to the local initial deflection. With $R$ and $\lambda$ equal to 1.2 and

0.1375 corresponding to the $20.7 \%$ decrease of load-bearing capacity. 
211 failure modes are demonstrated in Fig.11 taking two models as examples. The deformation of the columns

212 is detailed at two points. One is at the point of load-bearing capacity, and the other is at the $85 \%$ of the load-

213 bearing capacity after peak value. It can be recognized that coupled buckling or overall buckling occurs for

21412 combinations of width-thickness and slenderness ratios indicated by " $\mathrm{C} / \mathrm{O}$ " depending on the amplitudes

215 of initial deflections. For these combinations, the failure modes are detailed in Table 10. The failure mode

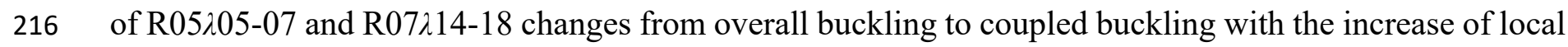

217 initial deflection from $b / 450$ to $b / 150$. Failure mode change of R05 $\lambda 09-18$ occurs when increasing initial

218 deflection from $b / 150$ to $b / 75$. This indicates that the amplitude of local initial deflection could change the

219 failure mode in the normalized width-thickness ratio range from 0.5 to 0.7 . The failure mode change by the

220 local initial deflection could result in the larger reduction of load-bearing capacity by it. Therefore, it could

221 be thought that this change is a cause inducing the movement of peak point of decreasing slope.

\subsection{Influence of the overall initial deflection}

Results of models with the normalized slenderness ratios $\lambda$ from 0.3 to 1.8 and constant normalized

width-thickness ratio $R$ of 0.9 are set as examples to show the influence of the overall initial deflection.

The comparison of load-bearing capacities for different overall initial deflection are shown in Fig.12. In

the case of $\lambda=0.3$, the reduction on load-bearing capacity by increasing overall initial deflection is less than

Relationship between the IDIC and the amplitude of the overall initial deflection normalized by the 
decreasing slope is nearly the same for different amplitudes of the local initial deflection.

Linear regression analysis is conducted on the data when the amplitude of the local initial deflection

234 is $b / 150$. The absolute values of the decreasing slope $\beta$ is related to the normalized slenderness ratio $\lambda$ as shown in Fig.14 in which six series of data with different normalized width-thickness ratio $R$ are plotted. It can be seen that the decreasing slope $\beta$ increases first and then decreases with the increase of the $\lambda$-value.

237 This tendency is similar to Fig. 10. However, being different from Fig. 10, the peak value of the decreasing 238 slope appears at almost the same $\lambda$-value of 1.4. As shown in Table 10, the amplitude of overall deflection 239 does not change the failure mode. This may be a cause of the difference.

With $\lambda$ from 0.7 to 1.8 , column load-bearing capacity becomes comparatively sensitive to overall initial deflection. The maximum decreasing slope ranges from 0.081 to 0.1166 . In addition, the influence of overall

242 initial deflection on load-bearing capacity is related to normalized width-thickness ratio $R$. With the dominated by overall buckling when $R$ is small. With $R$ and $\lambda$ equal to 0.3 and 1.4 , respectively, the influence reaches the maximum with the decreasing slope of 0.1166 corresponding to the $17.9 \%$ decrease of load246 bearing capacity.

\section{4. Formulation of the initial deflection influence coefficient}

\subsection{Proposed formulae}

In the previous chapter, the quantitative influence caused by the initial deflections on the load-bearing capacity was observed with a wide range of the normalized slenderness and width-thickness ratios taken

251 into consideration. The value of IDIC tends to decrease linearly as the local or overall initial deflections increase. The decreasing slope caused by the local/overall initial deflection is nearly invariable regardless 
of the amplitude of the overall/local initial deflection. This fact may suggest that there is no significant

254 coupling effect on IDIC between two initial deflections. Therefore, the IDIC can be calculated as,

$$
\mathrm{IDIC}=f(R, \lambda) *\left(I_{p}-1\right)+g(\lambda, R) *\left(I_{c}-1\right)+1
$$

In the formula, $f(R, \lambda)$ is the decreasing slope $\alpha, g(R, \lambda)$ is the decreasing slope $\beta$; $I_{p}$ is the local initial deflection normalized by the standard local initial deflection $(b / 150) ; I_{c}$ is the overall initial deflection normalized by the standard overall initial deflection $(L / 1000)$. The terms, $I_{p}, I_{c}$ minus 1 , are set to satisfy the condition that the IDIC is equal to 1 when the local and overall initial deflections are $b / 150$ and $L / 1000$,

262 respectively.

\subsection{Decreasing slope $\alpha$}

deflection is related with both normalized width-thickness ratio and slenderness ratio. As the width-

thickness ratio increases, the decreasing slope increases first then decreases after the peak value. In addition,

$$
f(R, \lambda)=p_{1} * R^{\left(p_{2}+p_{3} * R\right)}
$$

where $R$ and $\lambda$ is normalized width-thickness and slenderness ratios, respectively. 
regression analysis of the above numerical results with Levenberg-Marquardt method. It is understood that

275 the coefficients $p_{1}, p_{2}, p_{3}$ can be associated with the normalized slenderness ratio. Relationship between the

276 coefficients and the normalized slenderness ratio is plotted in Fig.15. The authors tried several functions

277 including linear, polynomial, logarithmic, exponential, trigonometric functions for the regression analysis.

278 As a result, the polynomial regression was adopted since it provided comparatively accurate prediction and

279 the formula format is simpler than others. The obtained formulae to estimate each coefficient are shown in 280 Eq. (8).

$$
\left\{\begin{array}{l}
p_{1}=-0.0384 \lambda^{4}+0.2037 \lambda^{3}-0.3362 \lambda^{2}+0.1511 \lambda-0.0958 \\
p_{2}=-5.8278 \lambda^{5}+35.7294 \lambda^{4}-80.1948 \lambda^{3}+78.3656 \lambda^{2}-30.3199 \lambda+7.0455 \\
p_{3}=-6.1618 \lambda^{4}+24.2455 \lambda^{3}-30.0485 \lambda^{2}+14.1142 \lambda-7.6727
\end{array}\right.
$$

\subsection{Decreasing slope $\beta$}

From the numerical results presented in Fig.14, it can be seen that the influence of overall initial ratio increases, the decreasing slope increases first, then decreases after the peak value. In addition, the peak value of the decreasing slope appears at almost the same $\lambda$-value of 1.4. The cubic function is assumed for the decreasing slope $\beta$ as Eq. (9),

$$
g(\lambda, \quad R)=q_{1}(\lambda-1.4)^{3}+q_{2}(\lambda-1.4)^{2}+q_{3}
$$

where $R$ and $\lambda$ are normalized width-thickness and slenderness ratios, respectively. 
regression analysis of the above numerical results. It is understood that the coefficients $q_{1}, q_{2}, q_{3}$ can be

associated with the normalized width-thickness ratio. Relationship between the coefficients and the normalized width-thickness ratio is plotted in Fig.16. By means of the polynomial regression, the formulae to estimate each coefficient are obtained as follows.

$$
\left\{\begin{array}{l}
q_{1}=0.037 R^{3}-0.0716 R^{2}-0.0126 R+0.0635 \\
q_{2}=0.0626 R^{3}-0.16 R^{2}+0.0584 R+0.1264 \\
q_{3}=-0.0252 R^{3}+0.0659 R^{2}-0.0228 R-0.1108
\end{array}\right.
$$

\section{Verification of the proposed formulae}

\subsection{Comparison between formulae and FEA results}

The IDICs obtained by the proposed formulae were compared with those by FEA for 378 models to verify the accuracy of the formulae. The comparisons are divided into seven figures by the normalized slenderness ratios as shown in Fig.17 (a)-(g). Additional 108 FEA results with normalized slenderness ratio of 0.9 and 1.2, which are not used in formula fitting analysis, are considered in formula verification procedure as shown in Fig.18. The absolute value of maximum errors and average errors between formulae results and FEA results are shown in Table 13 and Table 14, respectively. It can be seen that most of the formulae results show good agreement with FEA results with maximum errors less than 5\%. Only in four cases, the formulae results are found with errors more than $5 \%$, but less than $7 \%$. These relatively large errors are caused by the fact that the influence tendency of initial deflections is not strictly linear. Although the accuracy can be improved by considering the quadratic function on the influence tendency, the authors do not think that it is necessary due to accurate prediction results in most cases and more complicated 
calculation by using quadratic function.

Therefore, it can be concluded that the proposed IDIC formulae have sufficient accuracy and reliability

317 for estimating the quantitative influence of the initial deflections on the load-bearing capacity of the

unstiffened welded box section columns.

\subsection{Comparison between formulae and experimental results}

In Kishi's study [26], unstiffened box section members with a variety of the normalized slenderness

and width-thickness ratios were focused as a target. The standard initial deflections i.e. $b / 150$ for the local initial deflection and $L / 1000$ for the overall initial deflection were applied. Based on numerical analysis, a simplified formula Eq. (11) to predict the load-bearing capacity was proposed.

$$
\begin{gathered}
\sigma_{c r} / \sigma_{u}=1-\left(0.0502 \lambda^{2}-0.2485 \lambda+0.6077\right)(R-0.5) \\
\sigma_{u} / \sigma_{y}=\left\{\begin{array}{cr}
1 & \lambda \leq 0.2 \\
1.059-0.258 \lambda-0.190 \lambda^{2} & 0.2<\lambda \leq 1.0 \\
1.427-1.039 \lambda+0.223 \lambda^{2} & \lambda>1.0
\end{array}\right.
\end{gathered}
$$

where $\sigma_{c r}$ is the load-bearing capacity; $\sigma_{u}$ is the overall buckling strength of the column with the normalized slenderness ratio of $\lambda$ specified in the specification [14]; and $R$ is the normalized width-thickness ratio.

In this study, formulae to estimate the quantitative influence caused by the initial deflection are proposed. The product between the proposed formulae in this study and the existing simplified formula from Kishi will be the load-bearing capacity of the columns with actual amplitude of initial deflections. The comparison between current formulae and experimental results $[10,21]$ is shown in Table 15. Since the local initial deflection was not measured in Somodi's test [9], the test results of W3-series specimens were not used in this part. It can be seen that the existing formula considering initial deflections of $b / 150$ 
and $L / 1000$ comparatively underestimates the load-bearing capacity for all specimens. The product between

337 existing formula and IDICs provides better prediction on the load-bearing capacity.

\section{Influence of residual stress on initial deflection influence coefficient}

For the welded columns, residual stress would have significant influence on their load-bearing capacity.

According to previous statistics on residual stress of 216 normal strength steel columns by Fukumoto [26],

compressive residual stress varied from 0 to 0.6 . In this section, to investigate the influence of residual

stress on the initial deflection influence coefficient, specimens with short, medium and high columns length

were chosen for FE analysis with compressive residual stress $0.1 \sigma_{\mathrm{y}}$ and $0.4 \sigma_{\mathrm{y}}$. As mentioned in 3.2 and 3.3,

the initial deflection influence coefficient (IDIC) linearly decreases as the amplitude of local/overall initial

deflection increases. The decreasing slope is nearly the same for different amplitudes of overall/local initial

deflection. Therefore, the IDICs are plotted with normalized local initial deflection under the overall initial

deflection of $L / 1000$ as shown in Fig.19. Slight influence of residual stress on the relationship between

IDICs and local initial deflection can be observed. In general, the slope of the plot for smaller residual stress

is steeper, indicating larger influence of local initial deflection. For the columns with high slenderness ratio,

$0.4 \sigma_{\mathrm{y}}$. The relationship between IDICs and normalized overall initial deflection is plotted under the local initial deflection of $b / 150$ as shown in Fig.20. No clear influence of residual stress can be found on the relationship between IDICs and normalized overall initial deflection.

\section{Conclusions}

In this study, 486 models were analyzed to investigate the quantitative influence of the initial 
357 of normalized slenderness and width-thickness ratios. The main conclusions can be summarized as follows.

(1) The FE model established to predict the load-bearing capacity was verified through the comparison

359 with experimental results. The FEA results show good agreement with the experimental results with the 360 errors less than $6 \%$.

(2) The load-bearing capacity linearly decreases as the amplitude of local/overall initial deflection

362 increases. The decreasing slope is nearly the same for different amplitudes of overall/local initial 363 deflection.

(3) With the normalized width-thickness and slenderness ratios equal to 1.2 and 1.8, respectively, the influence of the local initial deflection reaches the maximum with the decreasing slope of 0.1375 corresponding to the $20.7 \%$ reduction on load-bearing capacity.

(4) With the normalized width-thickness and slenderness ratio equal to 0.3 and 1.4 , respectively, the influence of the overall initial deflection reaches the maximum with decreasing slope of 0.1166 corresponding to the $17.9 \%$ reduction on load-bearing capacity.

371 are developed, which describe the quantitative influence caused by the initial deflections. Compared with 372 the FEA results, the accuracy of the formulae is verified.

(6) Compared with the experimental results, it is verified that the product between the IDIC and the simplified formula can predict the load-bearing capacity with good accuracy in the case of columns with 375 various amplitudes of the initial deflections.

(7) The residual stress has slight influence on the relationship between IDICs and local initial deflection, while it has negligible influence on the relationship between IDICs and overall initial deflection. 
The validity of the proposed formulae has been evaluated only for the conditions examined in this

research. Their applicability to different cross-sections, residual stress pattern and high strength steel

380 columns as well as wider range of initial deflection value should be studied in the future work.

381 Acknowledgements

The research described in this paper is financially supported by China Scholarship Council

383 (No.201606650012).

$384 \quad$ References

[1] F. Bleich, Buckling strength of metal structure, McGraw-Hill, 1952.

[2] A. van der Neut, The interaction of local buckling and column failure of thin-walled compression members, in: Proceedings of the 12th International Congress on Applied Mechanics 1969, 389-399.

[3] T. Usami, Y. Fukumoto, Welded box compression members. Journal of Structural Engineering 1984,110 (10): 2457-2470.

[4] S.P. Chiew, S.L. Lee, N.E. Shanmugam, Experimental study of thin-walled steel box columns, Journal of Structural Engineering 1987, 113 (10): 2208-2220.

[5] A. van der Neut. The sensitivity of thin-walled compression members to column axis imperfection. International Journal of Solids and Structures 1973, 9(8): 999-1011.

[6] B. Li, M. Ahmer Wadee. Imperfection sensitivity of thin-walled I-section struts susceptible to cellular buckling. International Journal of Mechanical Sciences 2015, 104:162-73.

[7] T. Usami, Y. Fukumoto, Local and overall buckling of welded box columns, Journal of the Structural Division 1982, 108 (3): 525-542.

[8] K.J.R. Rasmussen, G.J. Hancock, Tests of high strength steel columns, Journal of Constructional Steel Research 1995, 34 (1): 27-52.

[9] B. Somodi, B. Kövesdi, Flexural buckling resistance of welded HSS box section members, Thin-Walled Structures 2017,119:266-281. 
[10] H. Degée, A. Detezel, U. Kuhlmann, Interaction of global and local buckling in welded RHS compression members, Journal of Constructional Steel Research 2008, 64: 755-765.

[11] G. Shi, W.J. Zhou, Y. Bai, C.C. Lin, Local buckling of $460 \mathrm{MPa}$ high strength steel welded section stub columns under axial compression, Journal of Constructional Steel Research 2014, 100: 60-70.

[12] GB 50017-2003, Code for Design of Steel Structures, China, 2003.(in Chinese)

[13] AISC, ANSI/AISC 360-16, Specification for Structural Steel Buildings, AISC, Chicago, 2016.

[14] Japan Road Association, Specifications for Highway Bridges, Part II Steel Bridges and Members, Japan, 2017.(in Japanese)

[15] Y.B. Kwon, E.G. Seo, Prediction of the compressive strength of welded RHS columns undergoing buckling interaction, Thin-Walled Structures 2013, 68: 141-155.

[16] K. Inose, M. Hirohata, Y. Nakanishi, Y.C. Kim, Ultimate strength of non-stiffened welded structural member assembled by using laser beam, Journal of Structural Engineering 2008, 54A: 50-57. (in Japanese) [17] Y. Lu, G. Shi, M.H. Zhao, W.J. Zhou, Research on interactive buckling behavior of welded steel boxsection columns, Thin-Walled Structures 2017, 115: 34-47.

[18] H.Y. Ban, G. Shi, Overall buckling behaviour and design of high-strength steel welded section columns, Journal of Constructional Steel Research 2018, 143: 180-195.

[19] Ana M. Girão Coelho, Pedro D. Simão, M. Ahmer Wadee, Imperfection sensitivity of column instability revisited, Journal of Constructional Steel Research 2013, 90: 265-282.

[20] S.B. Kang, B. Yang, X. Zhou, S.D. Nie, Global buckling behaviour of welded Q460GJ steel box columns under axial compression, Journal of Constructional Steel Research 2018, 140: 153-162.

[21] L. Pavlovčič, B. Froschmeier, U. Kuhlmann, D. Beg, Finite element simulation of slender thin-walled box columns by implementing real conditions, Advances in Engineering Software 2012, 44: 63-74.

[22] MARC user manual volume A - volume E. MSC Software Corporation, 2013.

[23] RD. Cook, SM. David, EP. Michael. Concepts and applications of finite element analysis. New York, 2007.

[24] B. Somodi, B. Kövesdi, Residual stress measurements on welded square box sections using seel grades of S235-S960, Thin-Walled Structures 2018,123:142-154. 
[25] Y. Fukumoto, Y. Itoh. Basic compressive strength of steel plates from test data. Proc. of JSCE 1984, 344(I-1):129-139.

[26] Y. Kishi, S. Nakamura, K. Ikezue, K. Nogami, H. Hirayama, T. Mizuguchi, M. Shirato, Numerical evaluation for coupled buckling strength of steel compression members with box section. The 14th East Asia-Pacific Conference on Structural Engineering and Construction, Vietnam, 2016, 1889-1896.

\section{Annex: An example to apply show the application procedure of the proposed formulae}

Test specimen W-S in Table 1 is set as an example to improve the accuracy of prediction on the load-bearing capacity. The basic parameter of W-S is tabulated below.

\begin{tabular}{ll}
\multicolumn{2}{c}{ Basic buckling parameter of $\mathrm{W}-\mathrm{S}$} \\
\hline Parameter & Value \\
\hline Normalized slenderness ratio $\lambda$ & 0.82 \\
Normalized width-thickness ratio $R$ & 0.95 \\
Overall initial deflection & $L / 1825$ \\
Local initial deflection & $b / 520$ \\
$\sigma_{T} / \sigma_{y}$ & 0.671 \\
\hline
\end{tabular}

Calculation according to Kishi's formula (Eq.(11)) and design code (Eq.(12)):

$$
\begin{gathered}
\sigma_{c r} / \sigma_{u}=1-\left(0.0502 \lambda^{2}-0.2485 \lambda+0.6077\right)(R-0.5)=0.803 \\
\sigma_{u} / \sigma_{y}=1.059-0.258 \lambda-0.190 \lambda^{2}=0.720 \\
\therefore \sigma_{c r} / \sigma_{y}=0.803 * 0.720=0.578
\end{gathered}
$$

Calculation of IDIC: Eqs. (6) - (10)

$$
\begin{aligned}
& \left\{\begin{array}{c}
p_{1}=-0.0384 \lambda^{4}+0.2037 \lambda^{3}-0.3362 \lambda^{2}+0.1511 \lambda-0.0958=-0.1030 \\
p_{2}=-5.8278 \lambda^{5}+35.7294 \lambda^{4}-80.1948 \lambda^{3}+78.3656 \lambda^{2}-30.3199 \lambda+7.0455=4.6527 \\
p_{3}=-6.1618 \lambda^{4}+24.2455 \lambda^{3}-30.0485 \lambda^{2}+14.1142 \lambda-7.6727=-5.7214
\end{array}\right. \\
& f(R, \lambda)=p_{1} * R^{\left(p_{2}+p_{3} * R\right)}=-0.1072
\end{aligned}
$$




$$
\begin{gathered}
\left\{\begin{array}{l}
q_{1}=0.037 R^{3}-0.0716 R^{2}-0.0126 R+0.0635=0.0186 \\
q_{2}=0.0626 R^{3}-0.16 R^{2}+0.0584 R+0.1264=0.0912 \\
q_{3}=-0.0252 R^{3}+0.0659 R^{2}-0.0228 R-0.1108=-0.0946
\end{array}\right. \\
\quad g(\lambda, R)=q_{1}(\lambda-1.4)^{3}+q_{2}(\lambda-1.4)^{2}+q_{3}=-0.0676 \\
\text { IDIC }=f(R, \lambda) *\left(I_{p}-1\right)+g(\lambda, R) *\left(I_{c}-1\right)+1=1.1068 \\
\therefore \sigma_{u, \text { formula }} / \sigma_{y}=\text { IDIC } * \sigma_{c r} / \sigma_{y}=1.1068 * 0.578=0.640
\end{gathered}
$$

Comparison with test results:

$$
\begin{gathered}
\frac{\sigma_{c r}-\sigma_{T}}{\sigma_{T}}=\frac{0.578-0.671}{0.671} * 100 \%=-13.9 \% \\
\frac{\sigma_{u, \text { formula }}-\sigma_{T}}{\sigma_{T}}=\frac{0.640-0.671}{0.671} * 100 \%=-4.6 \%
\end{gathered}
$$

It can be seen that the prediction by the simplified formula tends to underestimate the load-bearing capacity of the columns due to large initial deflections considered. When the actual amplitude of initial deflections is considered into the calculation by the proposed formulae, more accurate prediction on the load-bearing capacity can be obtained. 


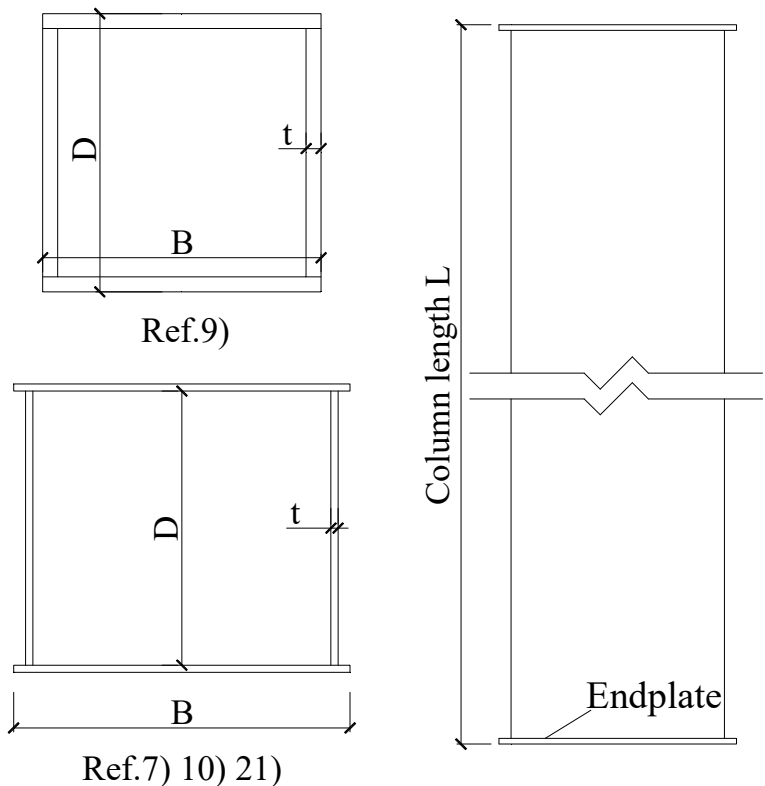

Fig. 1 Test specimens 


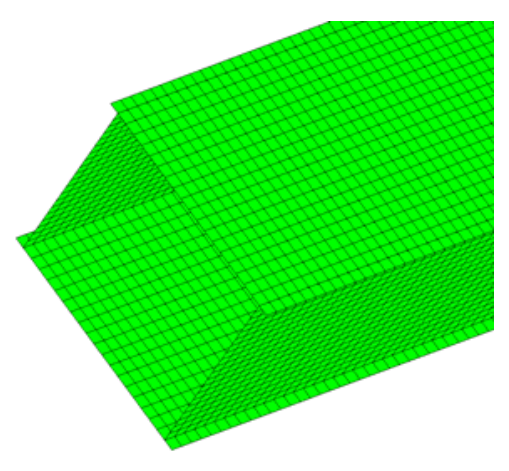

(a) Meshing profile

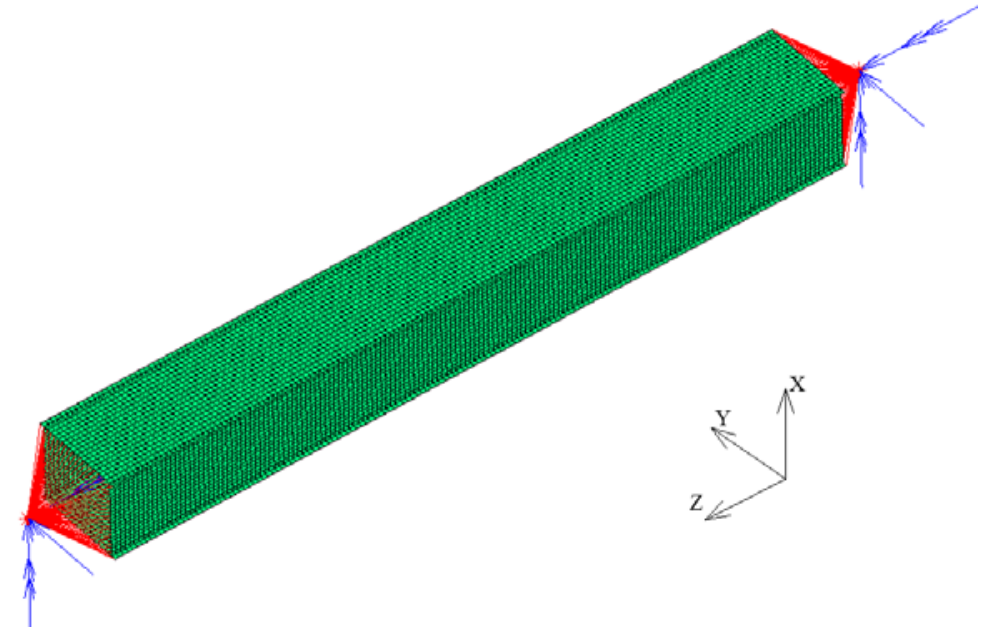

(b) Geometry and boundary condition of specimen 


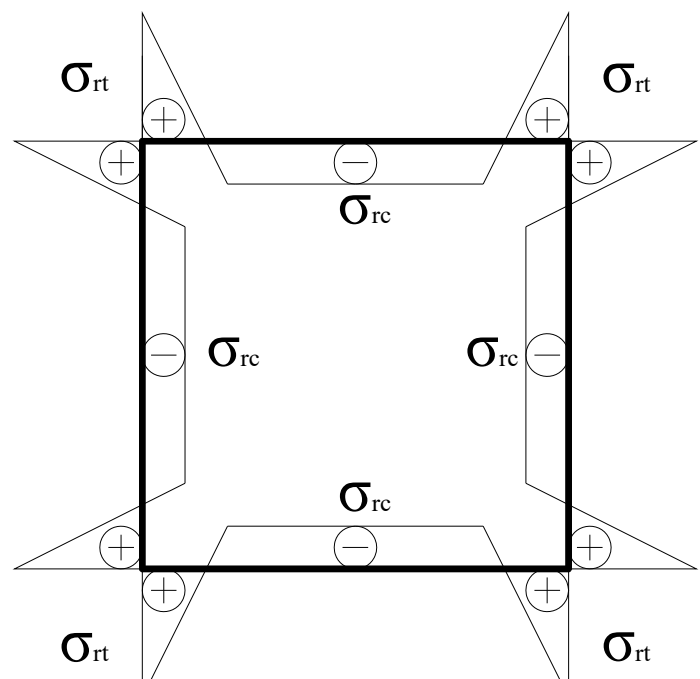

Fig. 3 Distribution of residual stress in the cross-section 


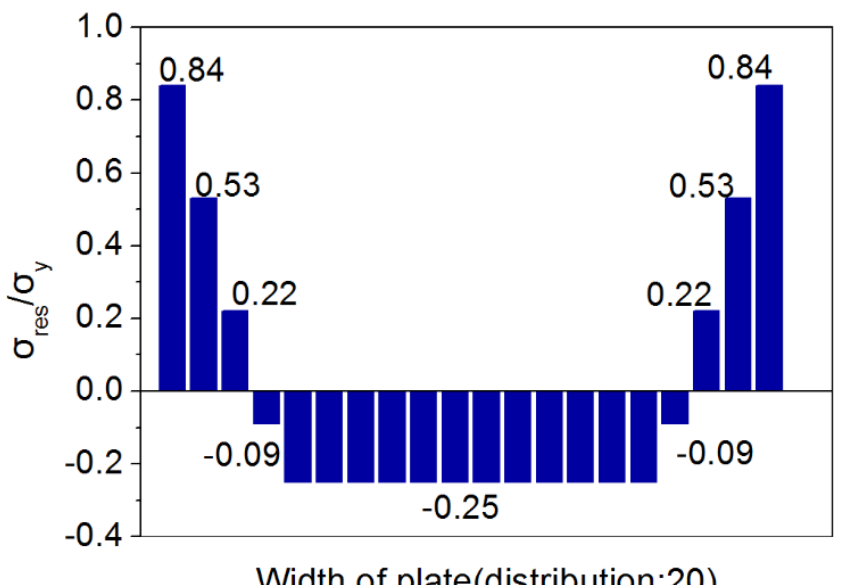

Fig. 4 Distribution of residual stress in every plate 


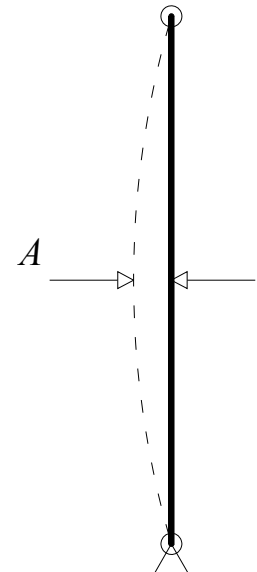

(a) Overall initial deflection shape

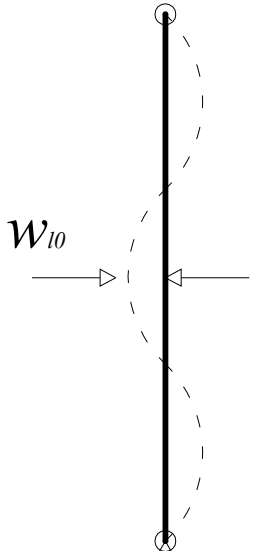

(b) Local initial deflection shape

Fig. 5 Initial deflection shape 


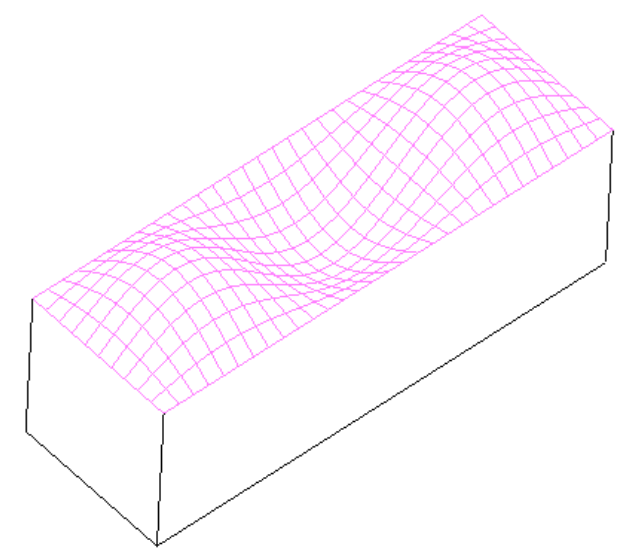

(a) Local initial deflection on one plate ( $m=3$ as an example)

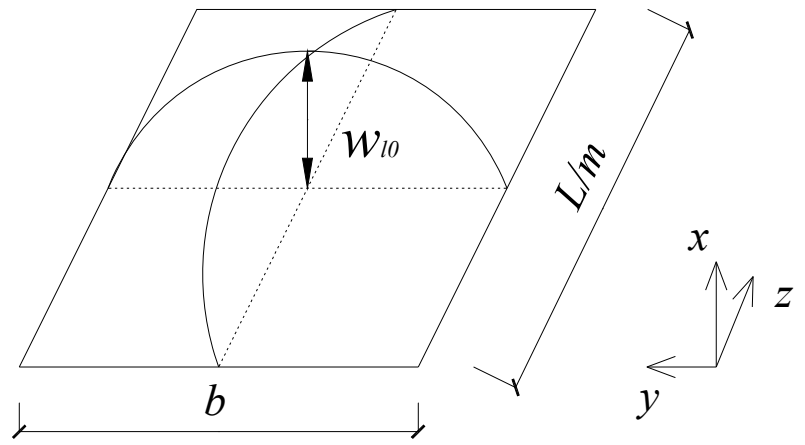

(b) Local initial deflection for half sin-wave

Fig. 6 Local initial deflection shape 


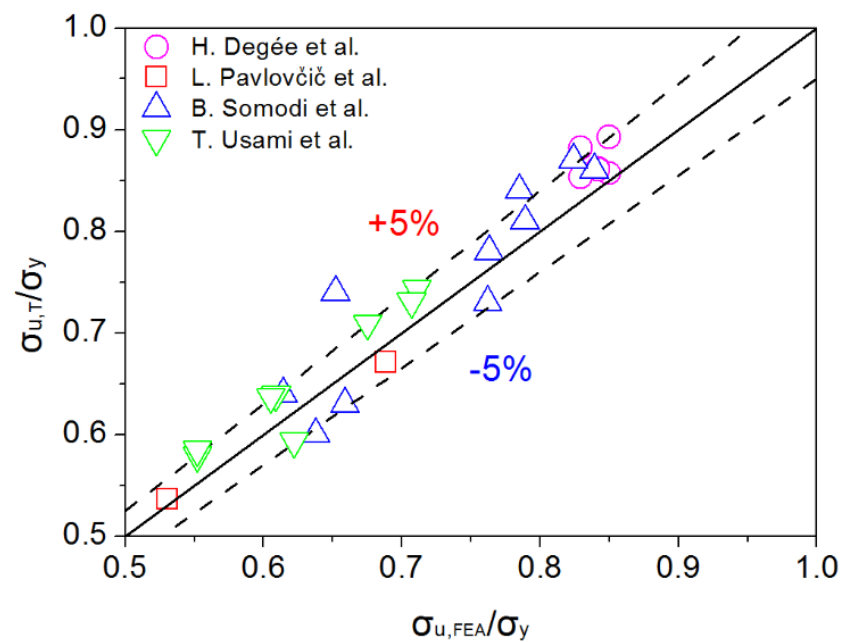

Fig. 7 Comparison of load-bearing capacity between experimental and FEA results 


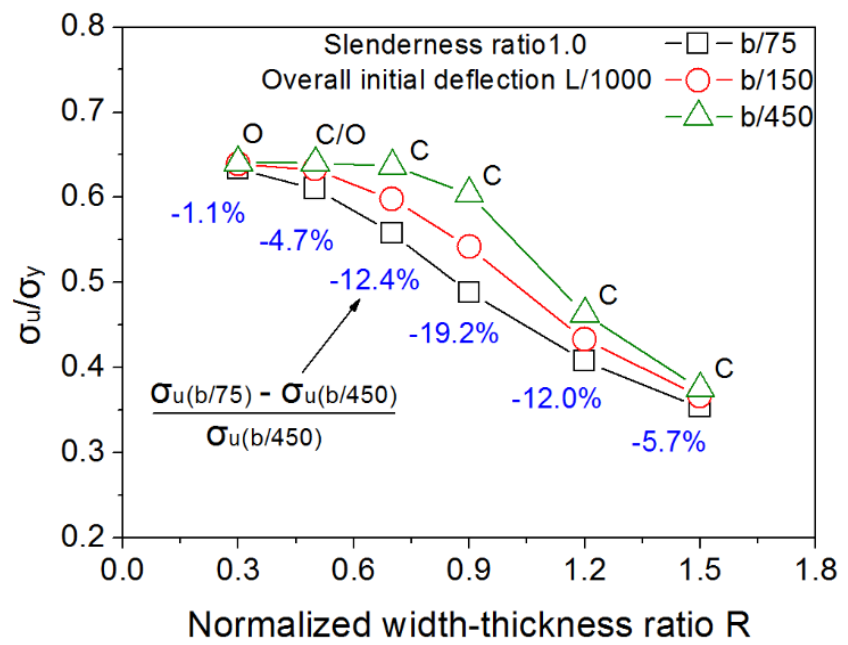

Fig. 8 Influence of local initial deflection on load-bearing capacity 


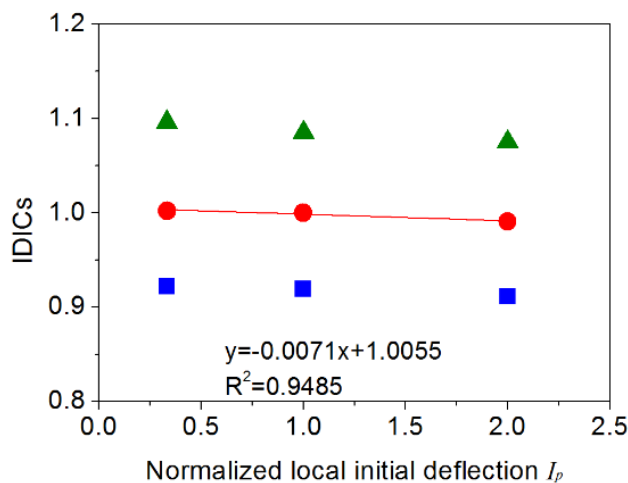

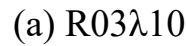

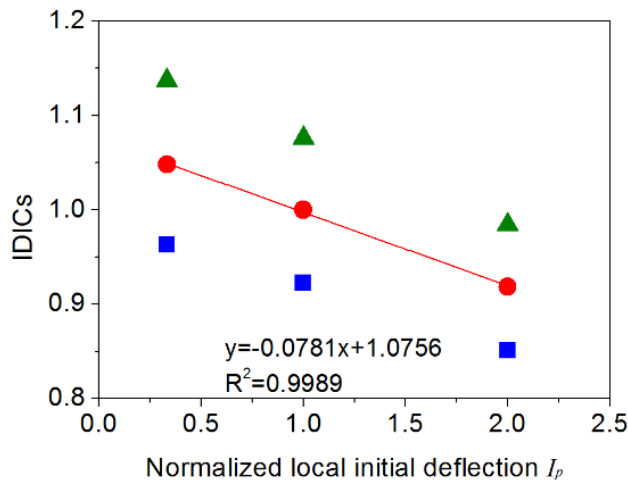

(c) $\mathrm{R} 07 \lambda 10$

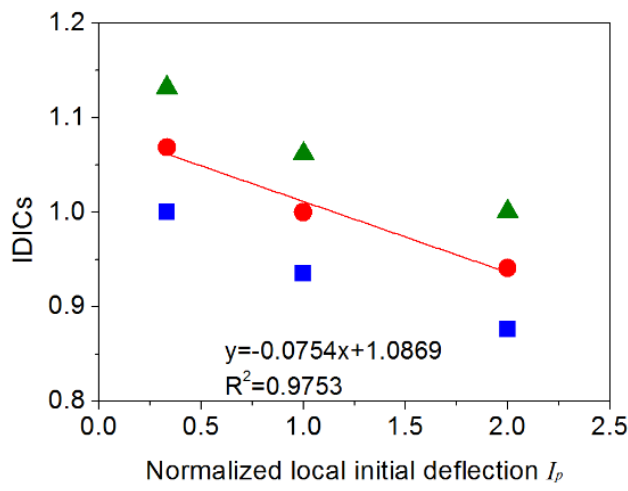

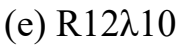

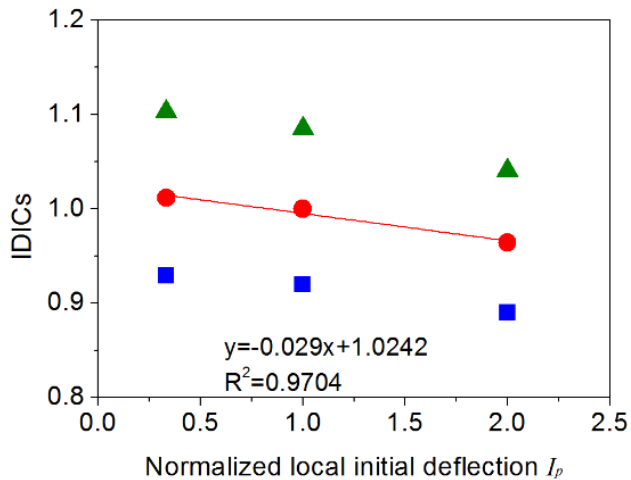

(b) $\mathrm{R} 05 \lambda 10$

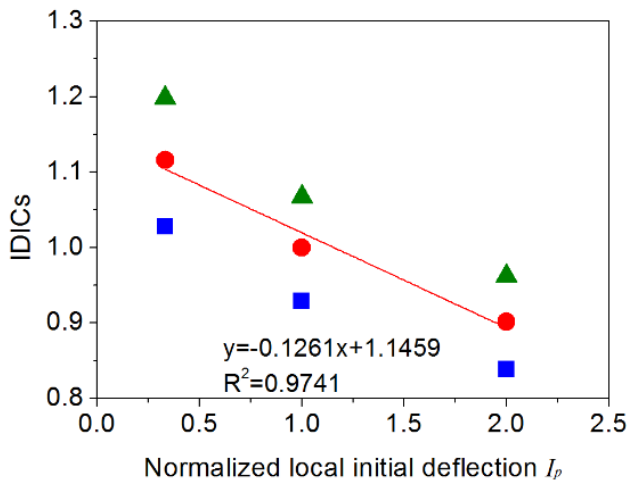

(d) $\mathrm{R} 09 \lambda 10$

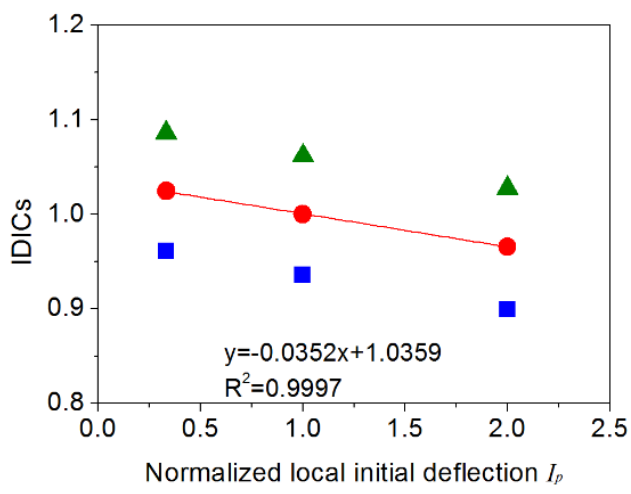

(f) $\mathrm{R} 15 \lambda 10$

Fig. 9 Initial deflection influence coefficient (IDICs) versus normalized local initial deflection 


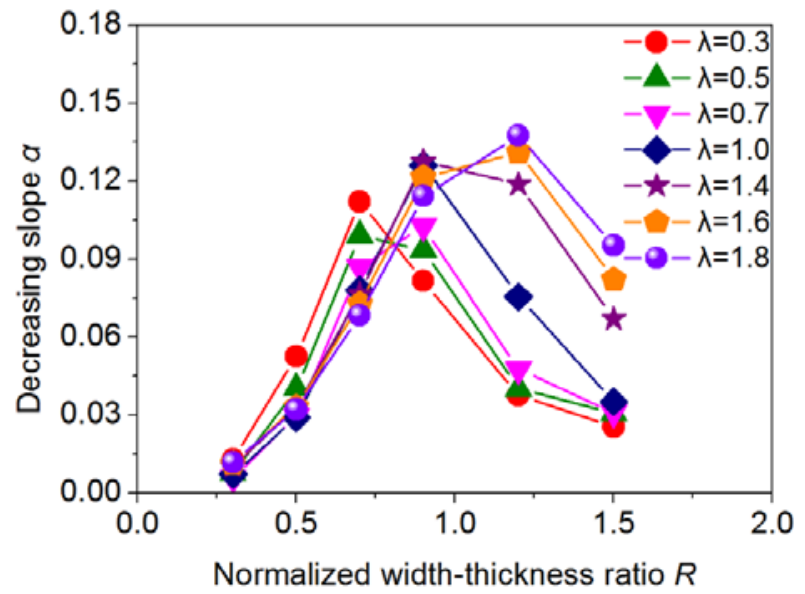

Fig. 10 Decreasing slope $\alpha$ versus normalized width-thickness ratio $R$ 


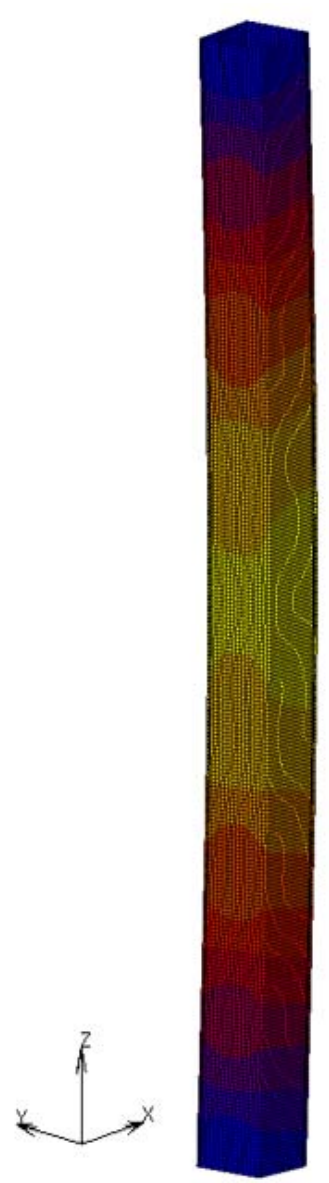

(a) at peak load

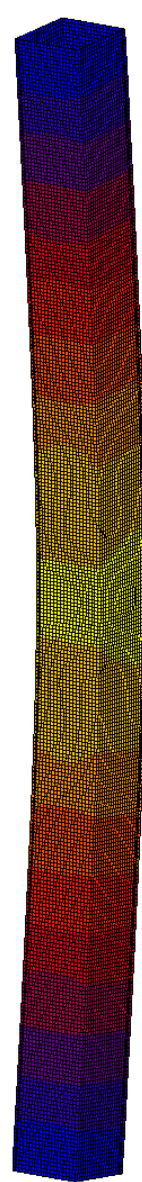

(b) at $85 \%$ after peak load

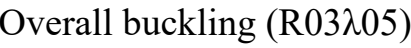

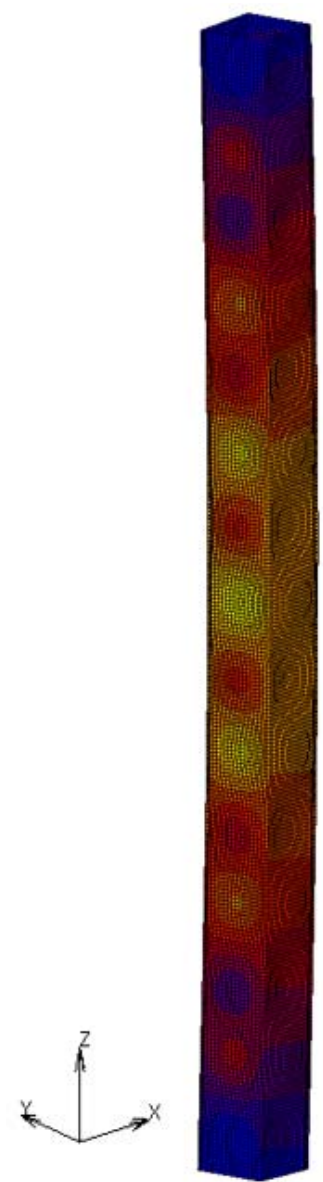

(c) at peak load

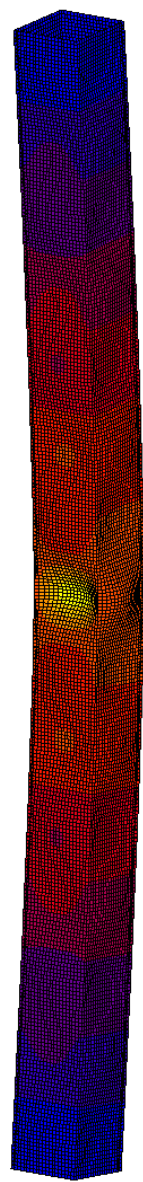

(d) at $85 \%$ after peak load Coupled buckling (R09705)

Fig. 11 Examples of deformed shape. (Amplifying factor:5) 


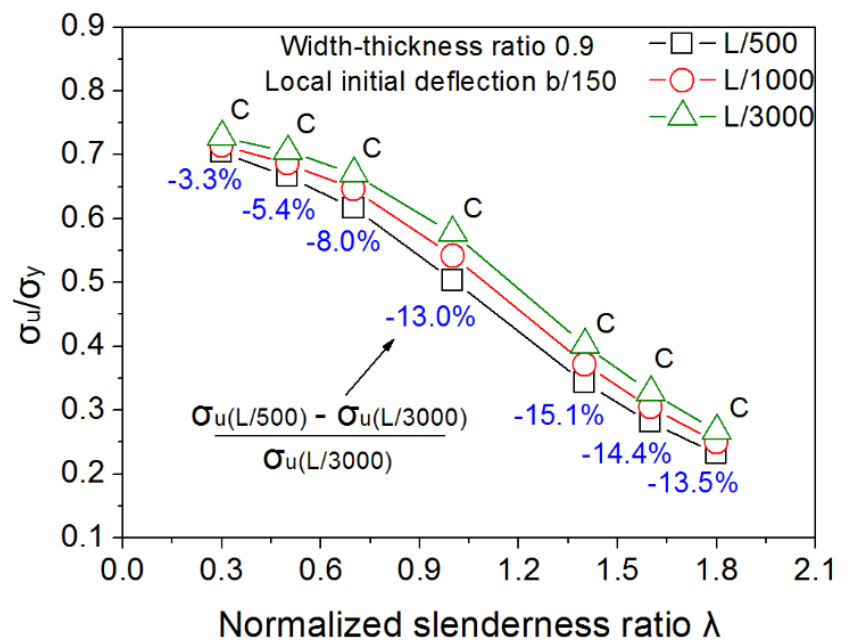

Fig. 12 Influence of overall initial deflection on load-bearing capacity 


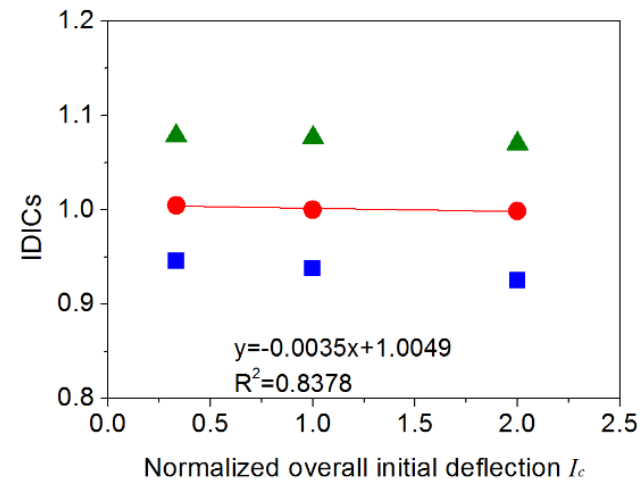

(a) R09 003

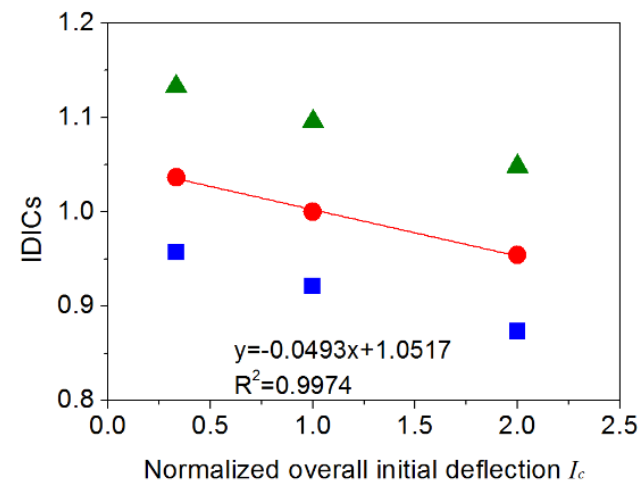

(c) R09 07

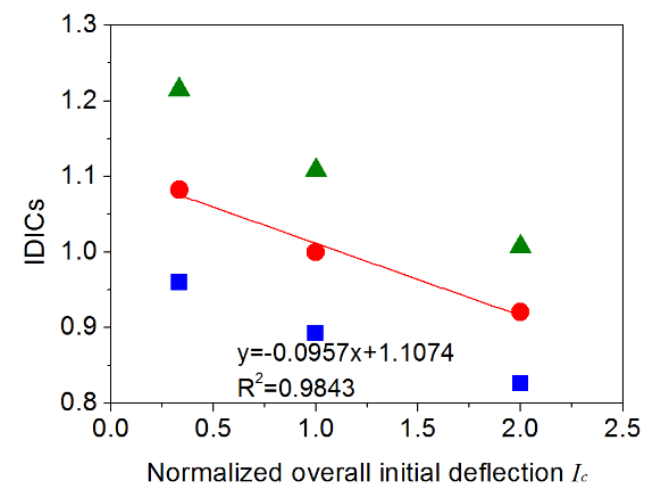

(e) $\mathrm{R} 09 \lambda 14$

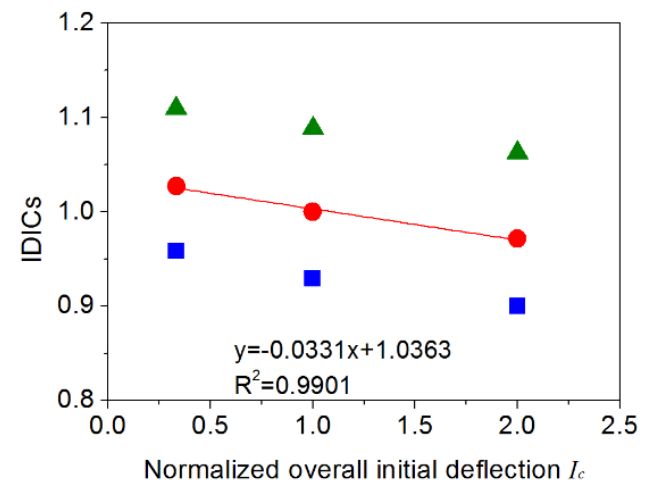

(b) R09 05

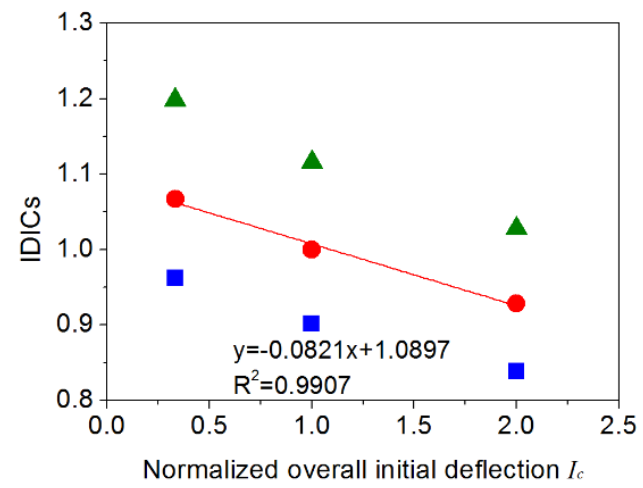

(d) R09 10

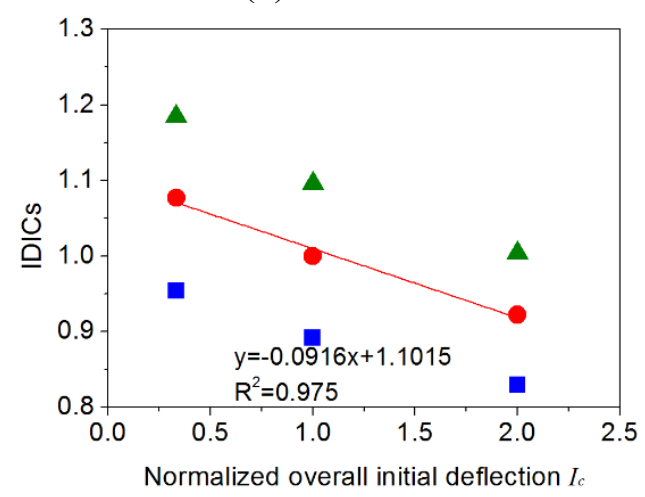

(f) R09ג16

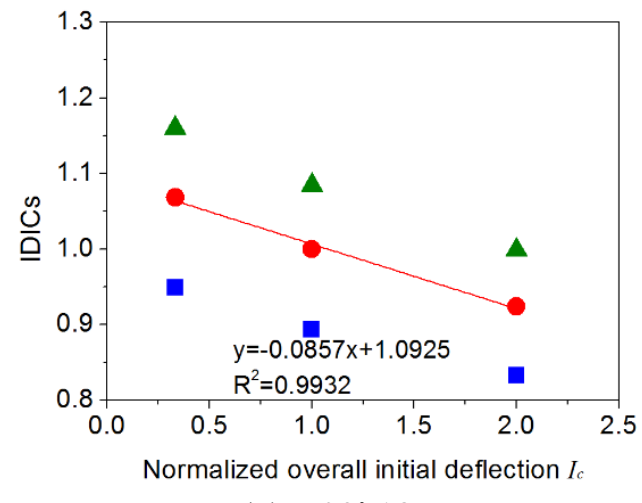

(g) R09 218

$b / 75 \bigcirc b / 150 \Delta b / 450$

Fig. 13 Initial deflection influence coefficient (IDICs) versus overall initial deflection 


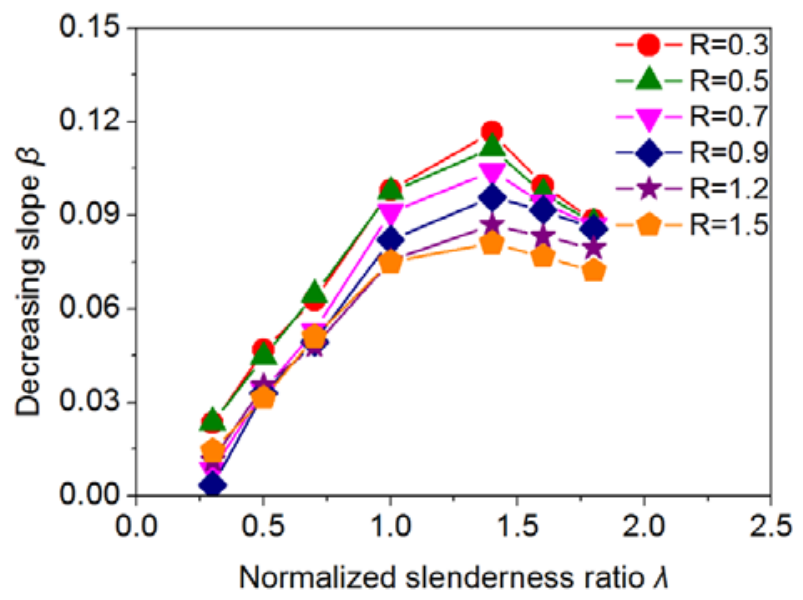

Fig. 14 Decreasing slope $\beta$ versus normalized slenderness ratio $\lambda$ 


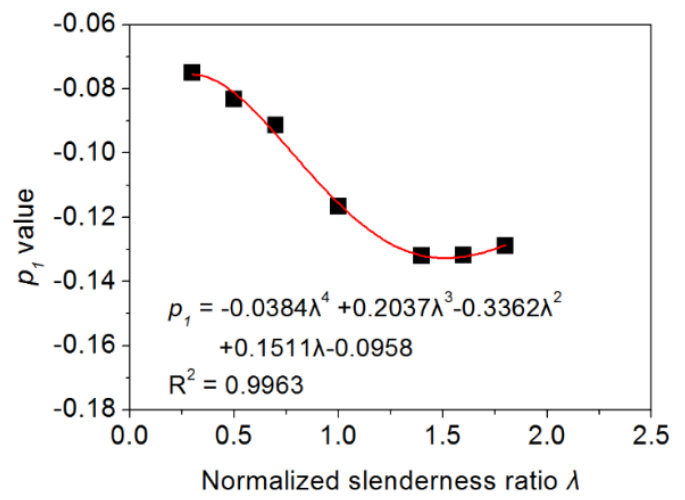

(a) Equation of $p_{1}$

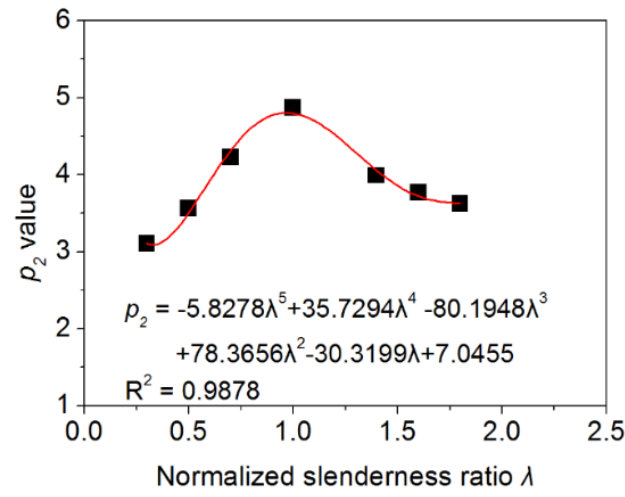

(b) Equation of $p_{2}$

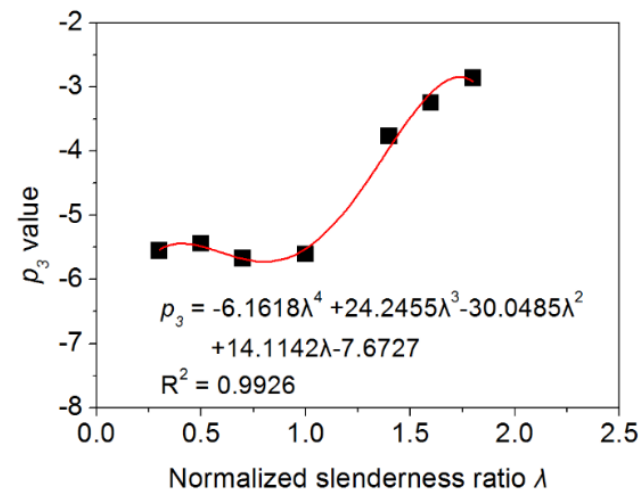

(c) Equation of $p_{3}$

Fig. 15 Equation of coefficient terms $p_{1}, p_{2}, p_{3}$ 


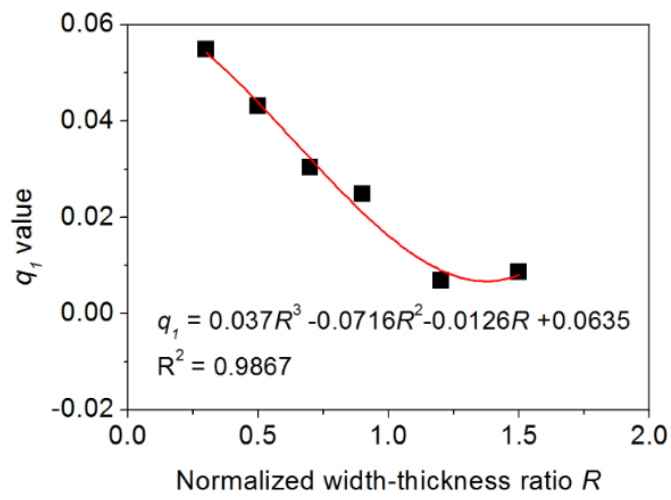

(a) Equation of $q_{1}$

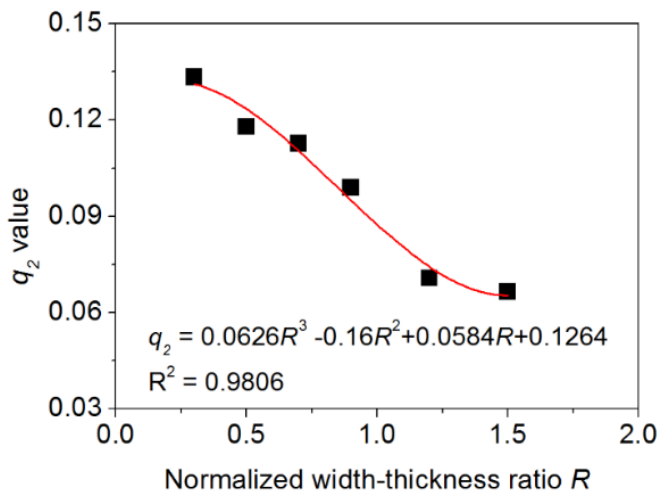

(b) Equation of $q_{2}$

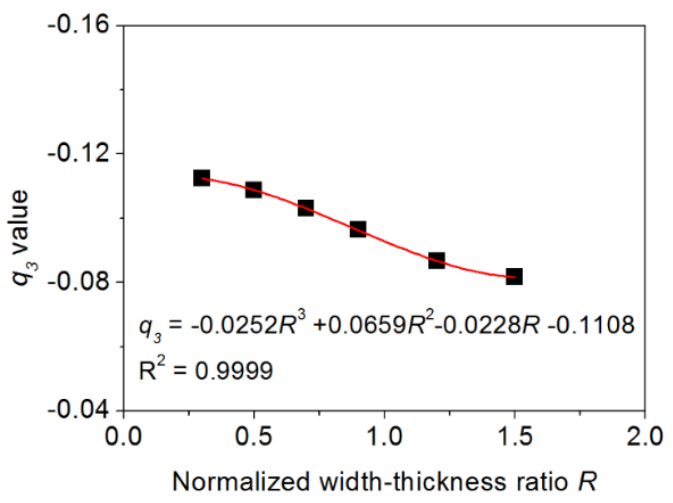

(c) Equation of $q_{3}$

Fig. 16 Equation of coefficient terms $q_{1}, q_{2}, q_{3}$ 


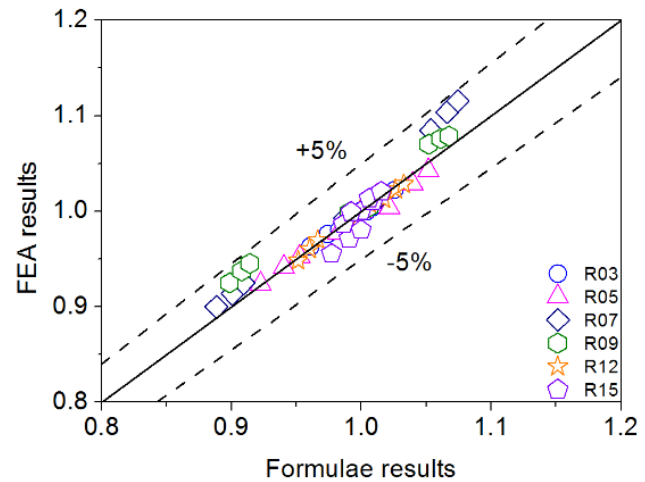

(a) $\lambda=0.3$

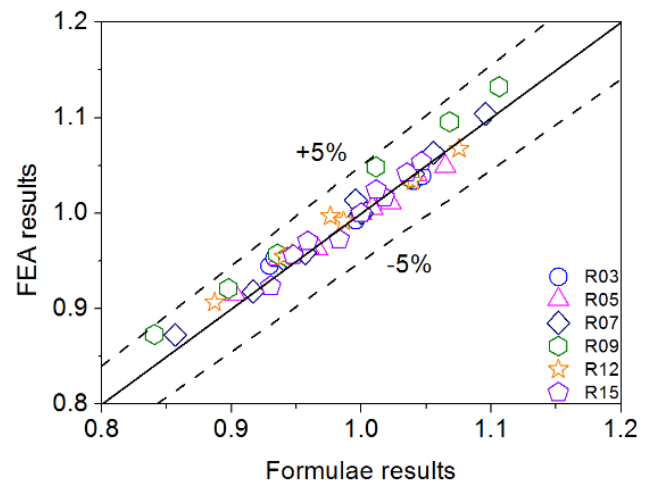

(c) $\lambda=0.7$

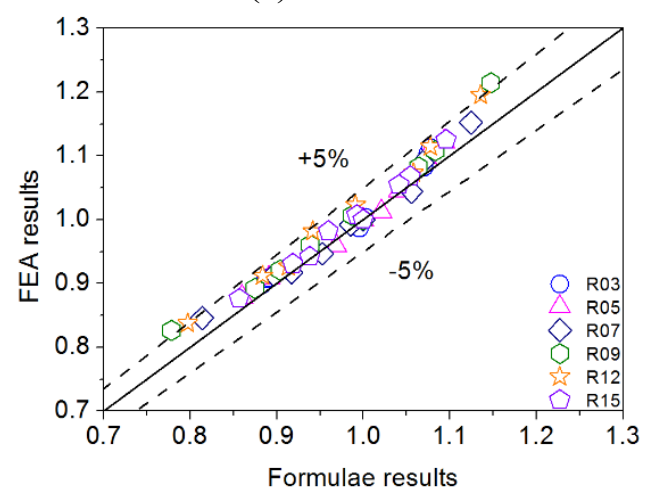

(e) $\lambda=1.4$

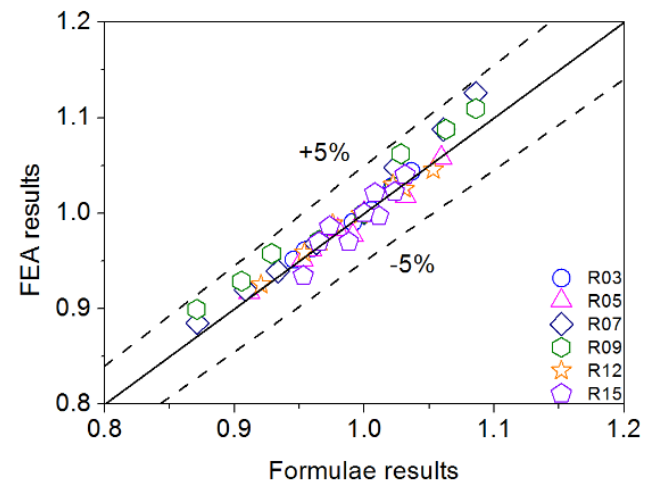

(b) $\lambda=0.5$

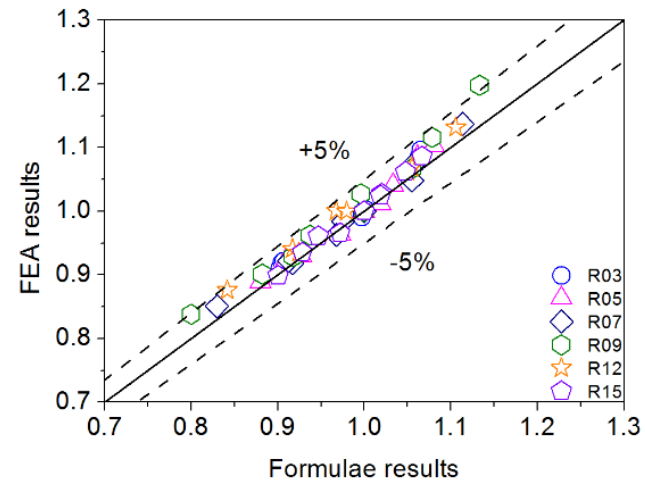

(d) $\lambda=1.0$

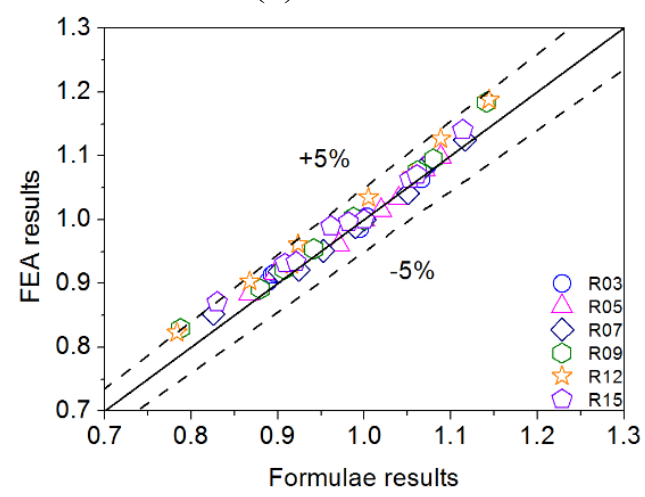

(f) $\lambda=1.6$

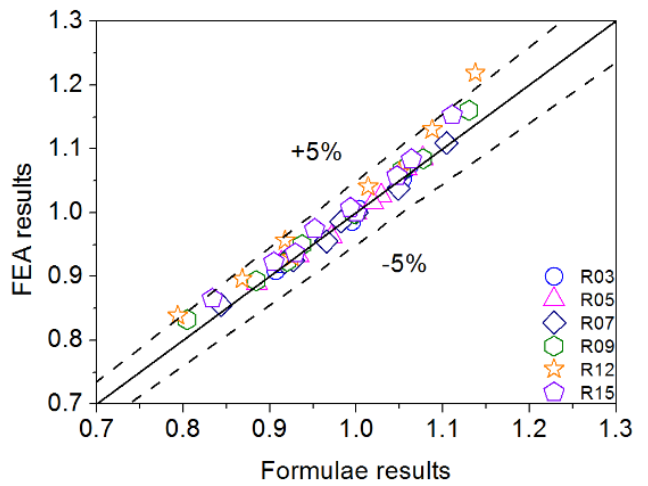

(g) $\lambda=1.8$

Fig. 17 Comparison of IDICs between formulae and FEA results 


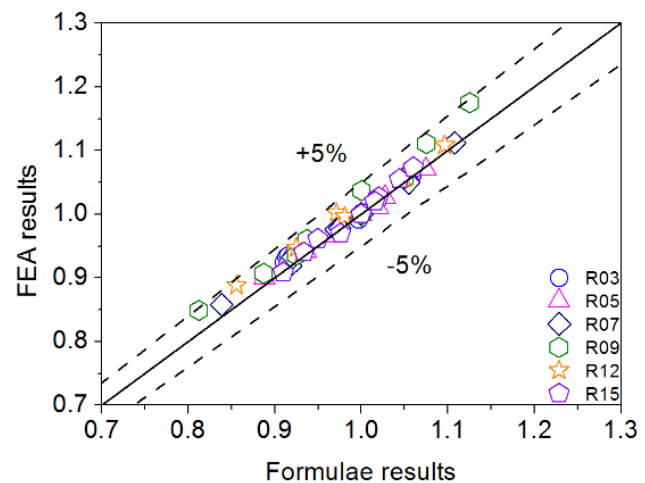

(a) $\lambda=0.9$

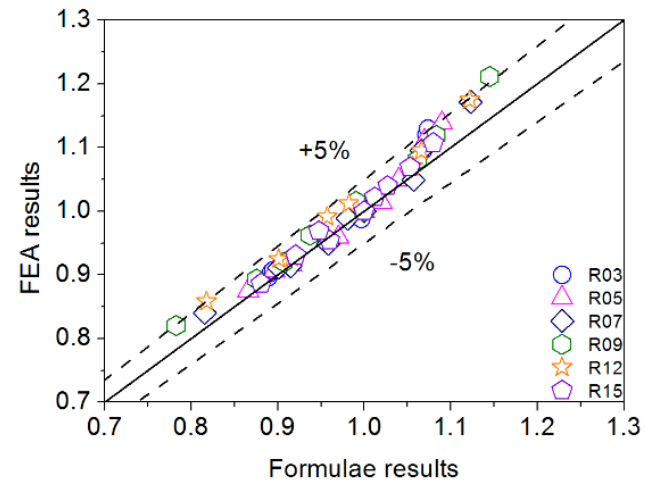

(b) $\lambda=1.2$

Fig. 18 Comparison of IDICs between formulae and FEA results 


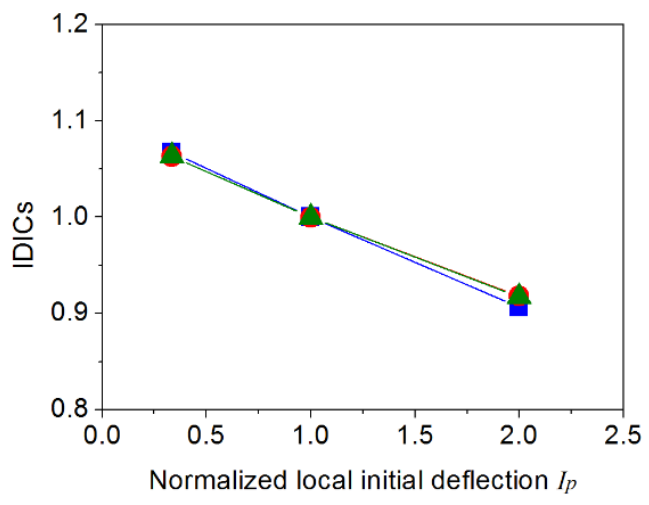

(a) $\mathrm{R} 07 \lambda 07$

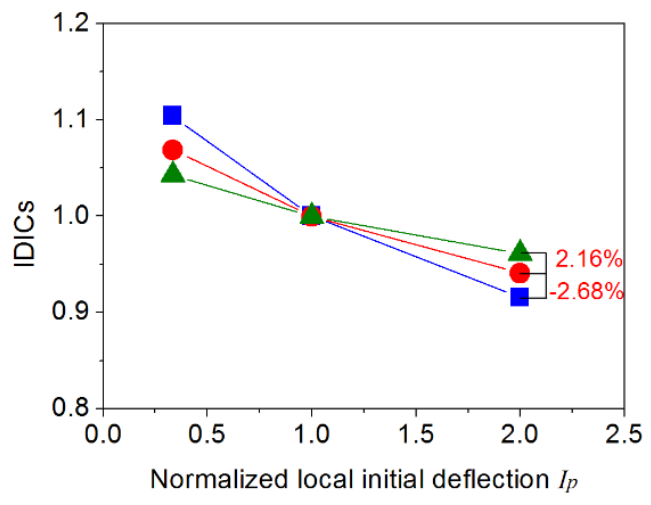

(c) $\mathrm{R} 12 \lambda 10$

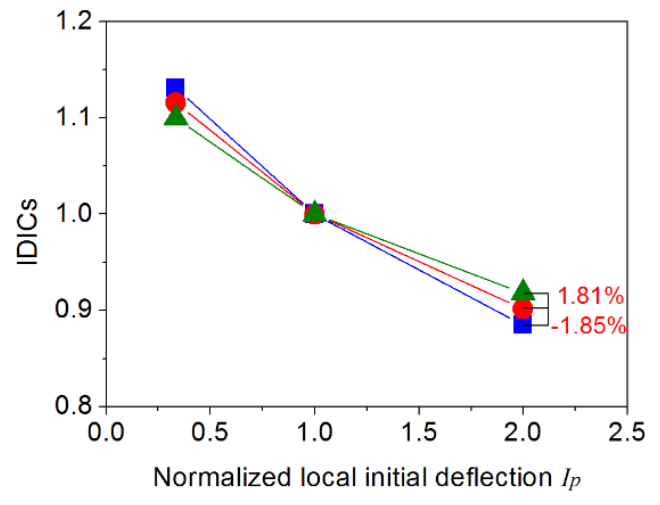

(b) R09ג10

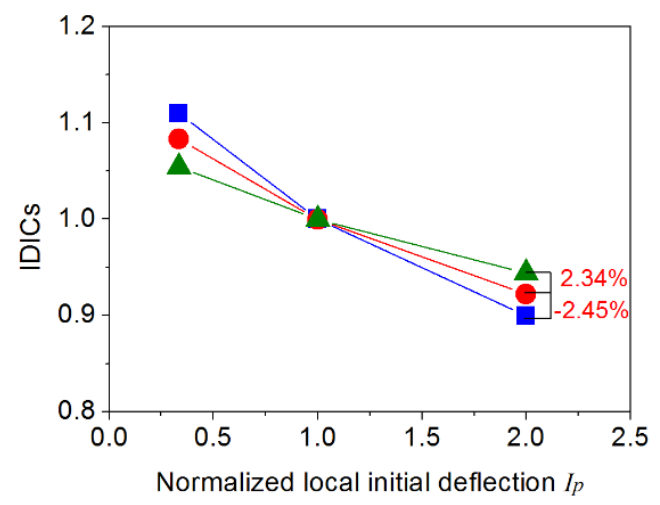

(d) $\mathrm{R} 15 \lambda 18$

Overall initial deflection L/1000

- RES0.1 - - RES0.25 - $\mathbf{\Delta}$-RES0.4

Fig. 19 Initial deflection influence coefficient (IDICs) versus normalized local initial deflection 


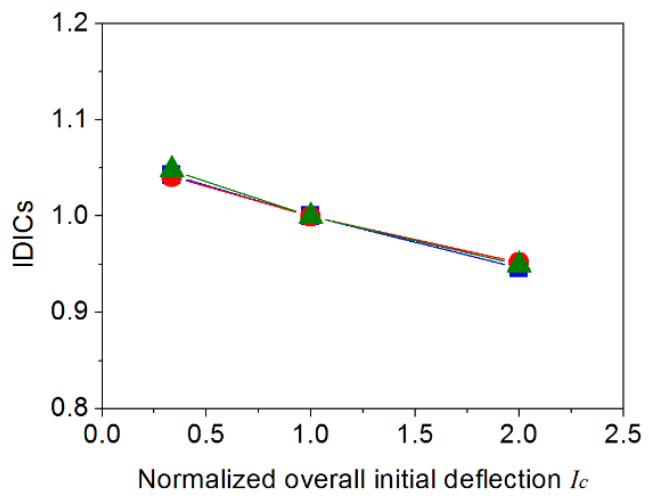

(a) R07 207

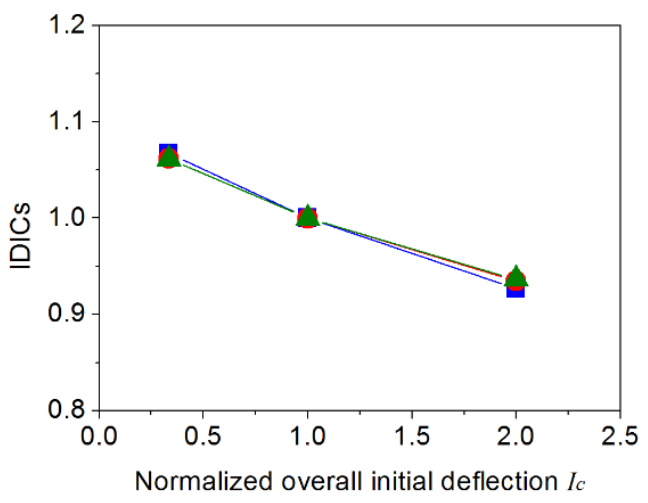

(c) $\mathrm{R} 12 \lambda 10$

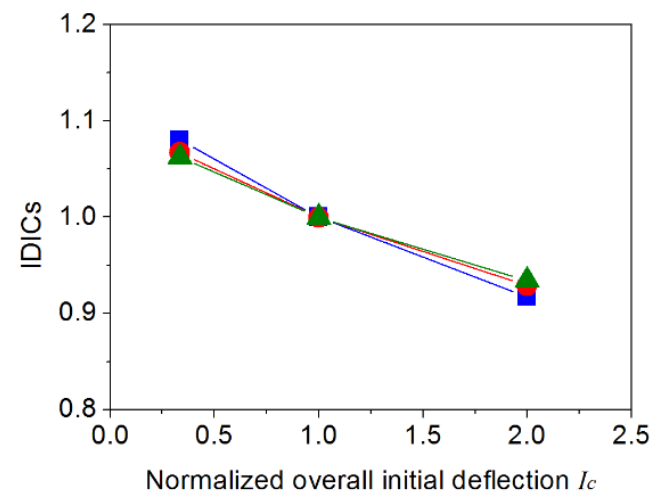

(b) R09 10

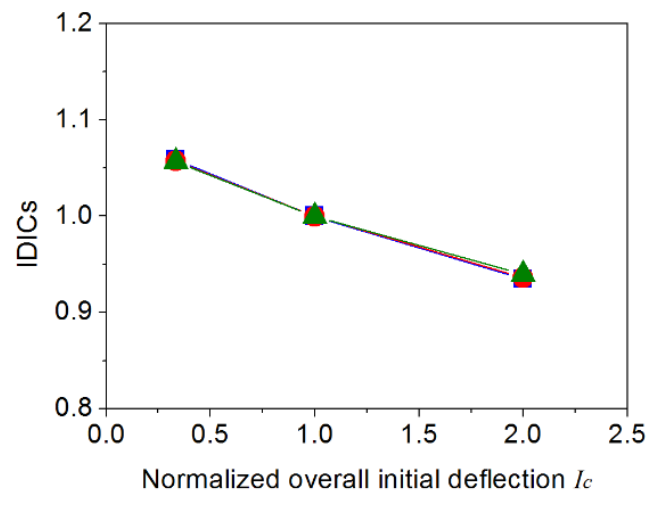

(d) $\mathrm{R} 15 \lambda 18$

Local initial deflection $\mathrm{b} / 150$

- $\mathbf{-}$-RES0.1 - - RES0.25 - $\mathbf{\Delta}$-RES0.4

Fig. 20 Initial deflection influence coefficient (IDICs) versus normalized overall initial deflection 
Table 1 Dimensions of experimental specimens

\begin{tabular}{|c|c|c|c|c|c|c|c|c|c|}
\hline Specimen & $B(\mathrm{~mm})$ & $D(\mathrm{~mm})$ & $t(\mathrm{~mm})$ & $L(\mathrm{~mm})$ & $L_{B}(\mathrm{~mm})$ & $\sigma_{y}(\mathrm{MPa})$ & $E(\mathrm{GPa})$ & $\lambda$ & $R$ \\
\hline $\mathrm{S} 1 \mathrm{a} / \mathrm{b}$ & 282 & 230 & 6 & 2200 & 2500 & 390 & 187 & 0.35 & 0.9 \\
\hline $\mathrm{S} 2 \mathrm{a} / \mathrm{b}$ & 282 & 230 & 6 & 3700 & 4000 & & & 0.55 & 0.9 \\
\hline $\mathrm{S} 3 \mathrm{a} / \mathrm{b}$ & 282 & 230 & 6 & 4900 & 5200 & & & 0.72 & 0.9 \\
\hline W-S & 200 & 152 & 4 & 3650 & 4000 & 373.4 & 205 & 0.82 & 0.95 \\
\hline W-L & 200 & 152 & 4 & 4850 & 5200 & & & 1.07 & 0.95 \\
\hline W3-120-6-1800A/B & 120 & 120 & 6.2 & 1800 & 1940 & 411 & 210 & 0.60 & 0.43 \\
\hline \multirow[t]{2}{*}{ W3-120-6-2500A/B } & 120 & 120 & 6.2 & 2500 & 2640 & 411 & & 0.80 & 0.43 \\
\hline & & & $/ 6.1$ & & & & & & $/ 0.44$ \\
\hline W3-120-6-2800A/B & 120 & 120 & 6.3 & 2800 & 2940 & 411 & & 0.90 & 0.42 \\
\hline W3-150-6-2800A/B & 150 & 150 & 6.1 & 2800 & 2940 & 393 & & 0.70 & 0.55 \\
\hline \multirow[t]{2}{*}{ W3-80-5-2000A/B } & 80 & 80 & 5.1 & 2000 & 2140 & 415 & & 0.99 & 0.34 \\
\hline & & & 15.3 & & & & & & $/ 0.33$ \\
\hline R-50-22 & 151 & 94.2 & 6 & 2090 & - & 741 & 215 & 0.91 & 0.69 \\
\hline R-50-27 & 181 & 116 & 6 & 2570 & & & & 0.93 & 0.84 \\
\hline R-50-33 & 217 & 144 & 6 & 3140 & & & & 0.92 & 1.03 \\
\hline R-50-38 & 247 & 166 & 6 & 3610 & & & & 0.92 & 1.18 \\
\hline R-50-44 & 283 & 193 & 6 & 4180 & & & & 0.93 & 1.36 \\
\hline R-65-22 & 151 & 94.4 & 6 & 2720 & & & & 1.19 & 0.68 \\
\hline R-65-27 & 181 & 116 & 6 & 3340 & & & & 1.20 & 0.84 \\
\hline R-65-33 & 217 & 143 & 6 & 4080 & & & & 1.20 & 1.03 \\
\hline
\end{tabular}

Table 2 Measured initial deflections

\begin{tabular}{|c|c|c|c|c|c|c|c|c|}
\hline Specimen & $w_{l 0}$ & $w_{g 0}$ & Specimen & $w_{l 0}$ & $w_{g 0}$ & Specimen & $w_{l 0}$ & $w_{g 0}$ \\
\hline S1a & $b / 250$ & $L / 2800$ & W3-120-6-1800A & - & $L / 534$ & R-50-22 & - & $L / 2538$ \\
\hline $\mathrm{S} 1 \mathrm{~b}$ & & $L / 2500$ & W3-120-6-1800B & & $L / 416$ & $R-50-27$ & & $L / 1938$ \\
\hline $\mathrm{S} 2 \mathrm{a}$ & & $L / 4000$ & W3-120-6-2500A & & $L / 1068$ & $\mathrm{R}-50-33$ & & $L / 20833$ \\
\hline $\mathrm{S} 2 \mathrm{~b}$ & & $L / 4000$ & W3-120-6-2500B & & $L / 1740$ & R-50-38 & & $L / 4081$ \\
\hline S3a & & $L / 4350$ & W3-120-6-2800A & & $L / 491$ & R-50-44 & & $L / 7246$ \\
\hline $\mathrm{S} 3 \mathrm{~b}$ & & $L / 3700$ & W3-120-6-2800B & & $L / 387$ & R-65-22 & & $L / 4132$ \\
\hline W-S & $b / 520$ & $L / 1825$ & W3-150-6-2800A & & $L / 733$ & $\mathrm{R}-65-27$ & & $L / 2604$ \\
\hline \multirow[t]{3}{*}{ W-L } & & $L / 1426$ & W3-150-6-2800B & & $L / 475$ & R-65-33 & & $L / 8928$ \\
\hline & & & W3-80-5-2000A & & $L / 1159$ & & & \\
\hline & & & W3-80-5-2000B & & $L / 721$ & & & \\
\hline
\end{tabular}

Where $w_{g 0}$ and $w_{l 0}$ are the amplitudes of overall and local initial deflections, respectively.

Table 3 Boundary conditions

\begin{tabular}{lllllll}
\hline DOF & $\mathrm{T}_{\mathrm{x}}$ & $\mathrm{T}_{\mathrm{y}}$ & $\mathrm{T}_{\mathrm{z}}$ & $\mathrm{R}_{\mathrm{x}}$ & $\mathrm{R}_{\mathrm{y}}$ & $\mathrm{R}_{\mathrm{z}}$ \\
\hline Mov & Fix & Fix & Free & Fix & Free & Fix \\
Fix & Fix & Fix & Fix & Fix & Free & Fix \\
\hline
\end{tabular}


Table 4 Residual stress used in FE model validation

\begin{tabular}{lllllllll}
\hline Specimen & $\sigma_{r t} / \sigma_{y}$ & $\sigma_{r c} / \sigma_{y}$ & Specimen & $\sigma_{r t} / \sigma_{y}$ & $\sigma_{r c} / \sigma_{y}$ & Specimen & $\sigma_{r t} / \sigma_{y}$ & $\sigma_{r c} / \sigma_{y}$ \\
\hline S1a & 0.6 & 0.04 & W3-120-6-1800A & 1.0 & 0.27 & R-50-22 & 0.6 & 0.1 \\
S1b & & & W3-120-6-1800B & & & R-50-27 & & \\
S2a & & & W3-120-6-2500A & & R-50-33 & & \\
S2b & & & W3-120-6-2500B & & R-50-38 & & \\
S3a & & & W3-120-6-2800A & & R-50-44 & & \\
S3b & & & W3-120-6-2800B & & R-65-22 & & \\
W-S & 1.0 & 0.35 & W3-150-6-2800A & 0.38 & R-65-27 & & \\
W-L & & $(0.43)$ & W3-150-6-2800B & & R-65-33 & & \\
& & & W3-80-5-2000A & 0.45 & & & \\
& & & W3-80-5-2000B & & & & \\
\hline
\end{tabular}

Table 5 load-bearing capacity obtained by the experimental and FEA results

\begin{tabular}{|c|c|c|c|c|c|c|c|}
\hline Specimen & $\sigma_{\mathrm{T}} / \sigma_{\mathrm{y}}$ & $\sigma_{\mathrm{FEA}} / \sigma_{\mathrm{y}}$ & Errors $(\%)$ & Specimen & $\sigma_{\mathrm{T}} / \sigma_{\mathrm{y}}$ & $\sigma_{\mathrm{FEA}} / \sigma_{\mathrm{y}}$ & Errors $(\%)$ \\
\hline S1a & 0.857 & 0.850 & -0.82 & W3-120-6-2800B & 0.6 & 0.638 & 6.33 \\
\hline S1b & 0.893 & 0.849 & -4.93 & W3-150-6-2800A & 0.81 & 0.789 & -2.59 \\
\hline S2a & 0.862 & 0.842 & -2.32 & W3-150-6-2800B & 0.78 & 0.763 & -2.18 \\
\hline $\mathrm{S} 2 \mathrm{~b}$ & 0.861 & 0.842 & -2.21 & W3-80-5-2000A & 0.74 & 0.652 & -11.89 \\
\hline S3a & 0.882 & 0.829 & -6.01 & W3-80-5-2000B & 0.64 & 0.614 & -4.06 \\
\hline $\mathrm{S} 3 \mathrm{~b}$ & 0.853 & 0.827 & -3.05 & $\mathrm{R}-50-22$ & 0.743 & 0.711 & -4.31 \\
\hline W-S & 0.671 & 0.689 & 2.68 & $\mathrm{R}-50-27$ & 0.731 & 0.707 & -3.28 \\
\hline W-L & 0.536 & 0.530 & -1.12 & $\mathrm{R}-50-33$ & 0.709 & 0.675 & -4.80 \\
\hline W3-120-6-1800A & 0.86 & 0.839 & -2.44 & $\mathrm{R}-50-38$ & 0.639 & 0.609 & -4.69 \\
\hline W3-120-6-1800B & 0.87 & 0.824 & -5.29 & R-50-44 & 0.579 & 0.552 & -4.66 \\
\hline W3-120-6-2500A & 0.73 & 0.762 & 4.38 & $\mathrm{R}-65-22$ & 0.593 & 0.622 & 4.89 \\
\hline W3-120-6-2500B & 0.84 & 0.785 & -6.55 & $\mathrm{R}-65-27$ & 0.637 & 0.605 & -5.02 \\
\hline W3-120-6-2800A & 0.63 & 0.659 & 4.60 & $\mathrm{R}-65-33$ & 0.585 & 0.552 & -5.64 \\
\hline Average Errors(\%) & -2.50 & & & & & & \\
\hline Standard DEV $(\%)$ & 4.07 & & & & & & \\
\hline
\end{tabular}

Table 6 Variable main properties of the numerical model

\begin{tabular}{ll}
\hline Parameter & Range of variable \\
\hline Dimension of cross-section & $500 \times 500 \mathrm{~mm}$ \\
Normalized slenderness ratio $\lambda$ & $0.3,0.5,0.7,1.0,1.4,1.6,1.8$ \\
Normalized width-thickness ratio $R$ & $0.3,0.5,0.7,0.9,1.2,1.5$ \\
Length of the column $L$ & $4572-27432 \mathrm{~mm}$ \\
Thickness of plate $t$ & $7.39-36.93 \mathrm{~mm}$ \\
\hline
\end{tabular}


Table 7 Combination of normalized slenderness and width-thickness ratios

\begin{tabular}{llllllll}
\hline Width-thickness & \multicolumn{6}{l}{ Slenderness ratio $\lambda$} \\
\cline { 2 - 8 } ratio $R$ & 0.3 & 0.5 & 0.7 & 1.0 & 1.4 & 1.6 & 1.8 \\
\hline 0.3 & $\mathrm{R} 03 \lambda 03$ & $\mathrm{R} 03 \lambda 05$ & $\mathrm{R} 03 \lambda 07$ & $\mathrm{R} 03 \lambda 10$ & $\mathrm{R} 03 \lambda 14$ & $\mathrm{R} 03 \lambda 16$ & $\mathrm{R} 03 \lambda 18$ \\
0.5 & $\mathrm{R} 05 \lambda 03$ & $\mathrm{R} 05 \lambda 05$ & $\mathrm{R} 05 \lambda 07$ & $\mathrm{R} 05 \lambda 10$ & $\mathrm{R} 05 \lambda 14$ & $\mathrm{R} 05 \lambda 16$ & $\mathrm{R} 05 \lambda 18$ \\
0.7 & $\mathrm{R} 07 \lambda 03$ & $\mathrm{R} 07 \lambda 05$ & $\mathrm{R} 07 \lambda 07$ & $\mathrm{R} 07 \lambda 10$ & $\mathrm{R} 07 \lambda 14$ & $\mathrm{R} 07 \lambda 16$ & $\mathrm{R} 07 \lambda 18$ \\
0.9 & $\mathrm{R} 09 \lambda 03$ & $\mathrm{R} 09 \lambda 05$ & $\mathrm{R} 09 \lambda 07$ & $\mathrm{R} 09 \lambda 10$ & $\mathrm{R} 09 \lambda 14$ & $\mathrm{R} 09 \lambda 16$ & $\mathrm{R} 09 \lambda 18$ \\
1.2 & $\mathrm{R} 12 \lambda 03$ & $\mathrm{R} 12 \lambda 05$ & $\mathrm{R} 12 \lambda 07$ & $\mathrm{R} 12 \lambda 10$ & $\mathrm{R} 12 \lambda 14$ & $\mathrm{R} 12 \lambda 16$ & $\mathrm{R} 12 \lambda 18$ \\
1.5 & $\mathrm{R} 15 \lambda 03$ & $\mathrm{R} 15 \lambda 05$ & $\mathrm{R} 15 \lambda 07$ & $\mathrm{R} 15 \lambda 10$ & $\mathrm{R} 15 \lambda 14$ & $\mathrm{R} 15 \lambda 16$ & $\mathrm{R} 15 \lambda 18$ \\
\hline
\end{tabular}

Table 8 Combinations of amplitude of initial deflections

\begin{tabular}{llllllllll}
\hline & Combi1 & Combi2 & Combi3 & Combi4 & Combi5 & Combi6 & Combi7 & Combi8 & Combi9 \\
\hline Local & $b / 75$ & $b / 75$ & $b / 75$ & $b / 150$ & $b / 150$ & $b / 150$ & $b / 450$ & $b / 450$ & $b / 450$ \\
Overall & $L / 500$ & $L / 1000$ & $L / 3000$ & $L / 500$ & $L / 1000$ & $L / 3000$ & $L / 500$ & $L / 1000$ & $L / 3000$ \\
\hline
\end{tabular}

Table 9 Failure modes in the FE models

\begin{tabular}{llllllll}
\hline \multirow{2}{*}{$\begin{array}{l}\text { Width-thickness } \\
\text { ratio } R\end{array}$} & \multicolumn{7}{l}{ Slenderness ratio $\lambda$} \\
\cline { 2 - 8 } & 0.3 & 0.5 & 0.7 & 1.0 & 1.4 & 1.6 & 1.8 \\
\hline 0.3 & $\mathrm{O}$ & $\mathrm{O}$ & $\mathrm{O}$ & $\mathrm{O}$ & $\mathrm{O}$ & $\mathrm{O}$ & $\mathrm{O}$ \\
0.5 & $\mathrm{C}$ & $\mathrm{C} / \mathrm{O}$ & $\mathrm{C} / \mathrm{O}$ & $\mathrm{C} / \mathrm{O}$ & $\mathrm{C} / \mathrm{O}$ & $\mathrm{C} / \mathrm{O}$ & $\mathrm{C} / \mathrm{O}$ \\
0.7 & $\mathrm{C}$ & $\mathrm{C}$ & $\mathrm{C}$ & $\mathrm{C}$ & $\mathrm{C} / \mathrm{O}$ & $\mathrm{C} / \mathrm{O}$ & $\mathrm{C} / \mathrm{O}$ \\
0.9 & $\mathrm{C}$ & $\mathrm{C}$ & $\mathrm{C}$ & $\mathrm{C}$ & $\mathrm{C}$ & $\mathrm{C}$ & $\mathrm{C}$ \\
1.2 & $\mathrm{C}$ & $\mathrm{C}$ & $\mathrm{C}$ & $\mathrm{C}$ & $\mathrm{C}$ & $\mathrm{C}$ & $\mathrm{C}$ \\
1.5 & $\mathrm{C}$ & $\mathrm{C}$ & $\mathrm{C}$ & $\mathrm{C}$ & $\mathrm{C}$ & $\mathrm{C}$ & $\mathrm{C}$ \\
\hline
\end{tabular}

Table 10 Failure mode change by initial deflections

(a) R05 $\lambda 05-07, \mathrm{R} 07 \lambda 14-18$

\begin{tabular}{llll}
\hline Overall initial deflection & \multicolumn{3}{l}{ Local initial deflection } \\
\cline { 2 - 4 } & $b / 75$ & $b / 150$ & $b / 450$ \\
\hline$L / 500$ & $\mathrm{C}$ & $\mathrm{C}$ & $\mathrm{O}$ \\
$L / 1000$ & $\mathrm{C}$ & $\mathrm{C}$ & $\mathrm{O}$ \\
$L / 3000$ & $\mathrm{C}$ & $\mathrm{C}$ & $\mathrm{O}$ \\
\hline
\end{tabular}

(b) R05 $210-18$

\begin{tabular}{llll}
\hline Overall initial deflection & \multicolumn{3}{l}{ Local initial deflection } \\
\cline { 2 - 4 } & $b / 75$ & $b / 150$ & $b / 450$ \\
\hline$L / 500$ & $\mathrm{C}$ & $\mathrm{O}$ & $\mathrm{O}$ \\
$L / 1000$ & $\mathrm{C}$ & $\mathrm{O}$ & $\mathrm{O}$ \\
$L / 3000$ & $\mathrm{C}$ & $\mathrm{O}$ & $\mathrm{O}$ \\
\hline
\end{tabular}


Table 11 Coefficient term and determination coefficient of equation $(L / 1000)$

\begin{tabular}{lllll}
\hline \multirow{2}{*}{$\begin{array}{l}\text { Slenderness } \\
\text { ratio } \lambda\end{array}$} & \multicolumn{2}{l}{ Coefficient term } & $\begin{array}{l}\text { Determination } \\
\text { coefficient }\end{array}$ \\
\cline { 2 - 4 } & $p_{1}$ & $p_{2}$ & $p_{3}$ & 0.9143 \\
0.3 & -0.0749 & 3.1002 & -5.5554 & 0.9254 \\
0.5 & -0.0834 & 3.5604 & -5.4439 & 0.9254 \\
0.7 & -0.0915 & 4.2250 & -5.6733 & 0.9478 \\
1.0 & -0.1168 & 4.8706 & -5.6100 & 0.9767 \\
1.4 & -0.1320 & 3.9886 & -3.7722 & 0.9924 \\
1.6 & -0.1318 & 3.7669 & -3.2494 & 0.9921 \\
1.8 & -0.1289 & 3.6211 & -2.8643 & 0.9906 \\
\hline
\end{tabular}

Table 12 Coefficient term and determination coefficient of equation $(b / 150)$

\begin{tabular}{lllll}
\hline \multirow{2}{*}{$\begin{array}{l}\text { Width-thickness } \\
\text { ratio } R\end{array}$} & \multicolumn{2}{l}{ Coefficient term } & $\begin{array}{c}\text { Determination } \\
\text { coefficient }\end{array}$ \\
\cline { 2 - 4 } & $q_{1}$ & $q_{2}$ & $q_{3}$ & 0.9853 \\
0.3 & 0.0548 & 0.1333 & -0.1124 & 0.983 \\
0.5 & 0.0431 & 0.1179 & -0.1087 & 0.9874 \\
0.7 & 0.0303 & 0.1126 & -0.1030 & 0.9896 \\
0.9 & 0.0248 & 0.0989 & -0.0963 & 0.9834 \\
1.2 & 0.0068 & 0.0706 & -0.0866 & 0.9873 \\
1.5 & 0.0086 & 0.0664 & -0.0817 & 0.9922 \\
\hline
\end{tabular}

Table 13 Maximum errors between formula and FEA results (\%)

\begin{tabular}{llllllllll}
\hline Width-thickness & \multicolumn{1}{l}{ Slenderness ratio $\lambda$} \\
\cline { 2 - 10 } ratio $R$ & 0.3 & 0.5 & 0.7 & 0.9 & 1.0 & 1.2 & 1.4 & 1.6 & 1.8 \\
\hline 0.3 & 0.44 & 0.89 & 2.04 & 2.03 & 2.82 & 4.89 & 3.12 & 2.17 & 1.09 \\
0.5 & 1.81 & 1.48 & 1.62 & 1.67 & 2.17 & 4.27 & 2.55 & 2.07 & 1.01 \\
0.7 & 3.68 & 3.57 & 1.81 & 2.25 & 2.47 & 4.17 & 3.81 & 3.08 & 1.36 \\
0.9 & 3.30 & 3.22 & 3.69 & 4.35 & 5.40 & 5.49 & 5.74 & 4.97 & 3.32 \\
1.2 & 0.46 & 1.33 & 2.19 & 3.68 & 3.91 & 4.77 & 4.99 & 4.74 & 6.68 \\
1.5 & 2.23 & 1.98 & 1.29 & 1.26 & 1.78 & 2.48 & 2.62 & 4.70 & 3.67 \\
\hline
\end{tabular}

Table 14 Average errors between formula and FEA results (\%)

\begin{tabular}{llllllllll}
\hline \multirow{2}{*}{$\begin{array}{l}\text { Width-thickness } \\
\text { ratio } R\end{array}$} & \multicolumn{9}{l}{ Slenderness ratio $\lambda$} \\
\cline { 2 - 10 } & 0.3 & 0.5 & 0.7 & 0.9 & 1.0 & 1.2 & 1.4 & 1.6 & 1.8 \\
\hline 0.3 & 0.32 & 0.51 & 1.02 & 0.85 & 1.37 & 1.99 & 1.68 & 1.17 & 0.63 \\
0.5 & 0.62 & 0.66 & 0.86 & 0.75 & 1.14 & 1.61 & 1.45 & 1.11 & 0.58 \\
0.7 & 1.87 & 1.54 & 0.85 & 0.78 & 1.18 & 1.69 & 1.56 & 1.04 & 0.79 \\
0.9 & 1.80 & 2.18 & 2.27 & 2.73 & 2.94 & 2.96 & 2.89 & 2.15 & 1.34 \\
1.2 & 0.28 & 0.61 & 1.11 & 1.78 & 2.19 & 2.94 & 3.31 & 3.18 & 3.42 \\
1.5 & 1.05 & 1.17 & 0.84 & 0.74 & 0.93 & 1.33 & 1.60 & 2.14 & 2.07 \\
\hline
\end{tabular}


Table 15 Comparison between formula and experimental results

\begin{tabular}{llllllll}
\hline Specimen & $\mathrm{F}_{\mathrm{T}}(\mathrm{kN})$ & $\bar{\sigma}_{\mathrm{T}}$ & $\bar{\sigma}_{\mathrm{cr}}$ & IDIC & IDIC* $\bar{\sigma}_{\mathrm{cr}}$ & $\begin{array}{l}\left(\bar{\sigma}_{\mathrm{cr}}-\bar{\sigma}_{\mathrm{T}}\right) \\
\left(\bar{\sigma}_{\mathrm{T}}(\%)\right.\end{array}$ & $\begin{array}{l}\left(\mathrm{IDIC} * \bar{\sigma}_{\mathrm{cr}}-\bar{\sigma}_{\mathrm{T}}\right) \\
/ \bar{\sigma}_{\mathrm{T}}(\%)\end{array}$ \\
\hline S1a & 2053 & 0.857 & 0.730 & 1.0471 & 0.764 & -14.8 & -10.9 \\
$\mathrm{~S} 1 \mathrm{~b}$ & 2139 & 0.893 & 0.730 & 1.0464 & 0.764 & -18.3 & -14.4 \\
$\mathrm{~S} 2 \mathrm{a}$ & 2065 & 0.862 & 0.711 & 1.0689 & 0.760 & -17.5 & -11.8 \\
$\mathrm{~S} 2 \mathrm{~b}$ & 2062 & 0.861 & 0.711 & 1.0689 & 0.760 & -17.4 & -11.7 \\
S3a & 2114 & 0.882 & 0.684 & 1.0868 & 0.743 & -22.4 & -15.8 \\
S3b & 2044 & 0.853 & 0.684 & 1.0844 & 0.742 & -19.8 & -13.0 \\
W-S & 706 & 0.671 & 0.578 & 1.1068 & 0.640 & -13.9 & -4.6 \\
W-L & 564 & 0.536 & 0.468 & 1.1123 & 0.521 & -12.7 & -2.8 \\
\hline
\end{tabular}

Where $\mathrm{F}_{\mathrm{T}}$ is the experimental results, $\bar{\sigma}$ is the non-dimensional load-bearing capacity, $\bar{\sigma}_{\mathrm{cr}}$ is calculated based on the Kishi's formula and specification formula, IDIC is an initial deflection influence coefficient. 